\title{
Un escenario para las élites: la Filarmónica de Madrid (1872-1874) y su producción sinfónica
}

\author{
A Stage for the Elite: \\ la Filarmónica de Madrid (1872-1874) and its \\ Symphonic Output
}

En 1872 se funda la Filarmónica de Madrid, una sociedad desconocida hasta la fecha, creada por varios nobles y que durará solamente hasta 1874. En este corto periodo programan cerca de veinte conciertos en la Escuela de Nacional de Música y Declamación. Entre las obras elegidas se combinan las de cámara y las sinfónicas, contando la orquesta con no más de cuarenta músicos en sus mejores momentos. La actividad de la agrupación entronca con la de la Sociedad de Conciertos, buscando cimentar el sinfonismo en España. A través del presente artículo se estudiará su formación, reglamento, público y repertorio, dando una mayor visibilidad a las obras de compositores españoles creadas ex profeso.

Palabras clave: Filarmónica de Madrid, sinfonismo, orquesta, repertorio, público, siglo XIX.

Founded in 1872, the Filarmónica de Madrid is a little-known society created by several noblemen that would only survive until 1874. In this short period, close to 20 concerts were programmed at the Escuela de Nacional de Música y Declamación. The works chosen for these concerts included a blend of chamber and symphonic music, the orchestra consisting of no more than 40 musicians at its peak. The society's activity is related to that of the Sociedad de Conciertos, which strived to consolidate symphonism in Spain. The present article will examine the Filarmónica's formation, regulations, audience and repertoire, which gave greater visibility to works by Spanish composers created especially for it.

Keywords: Filarmónica de Madrid, symphonism, orchestra, repertoire, audience, nineteenth century.

Hablar de la música sinfónica del siglo XIX en España es hablar de la Sociedad de Conciertos de Madrid. Los estudios que ha llevado a cabo Ramón Sobrino han erigido esta agrupación como modelo de asociacionismo musical decimonónico, siendo la primera orquesta independiente de la capital que se dedicó a la interpretación de obras íntegramente sinfónicas ${ }^{1}$. Aunque en sus inicios la agrupación interpretó obras con coro

${ }^{1}$ La Sociedad de Conciertos ha sido estudiada por Ramón Sobrino en su tesis doctoral "El sinfonismo español en el siglo XIX: La Sociedad de Conciertos de Madrid”, Universidad de Oviedo, 1993 (inédita). Sobre este tema ha publicado varios trabajos: "La Sociedad de Conciertos de Madrid, un mo- 
bajo la dirección de Francisco Asenjo Barbieri, pronto se suprimió esta práctica para dar cabida casi exclusivamente a obras contemporáneas, tanto extranjeras como nacionales, bajo la batuta de Jesús de Monasterio o Tomás Bretón, entre otros. Las obras de compositores españoles fueron recogidas modernamente en un catálogo publicado por Sobrino en 1990 y, desde entonces, han llamado la atención de diversas orquestas ${ }^{2}$. La actividad de recuperación a través de la edición crítica de partituras y también de grabaciones ha contribuido a tener una visión más adecuada sobre el sinfonismo de esa época ${ }^{3}$. La Sociedad de Conciertos dio respuesta musical a la esfera pública madrileña, ofreciendo estos conciertos a un gran grupo de personas.

Los conciertos multitudinarios que se daban en los Jardines del Buen Retiro o el Teatro del Príncipe Alfonso contrastaban con las prácticas que tenían lugar en la privacidad de los salones particulares. Celsa Alonso ha escrito sobre un panorama diferente en sus investigaciones sobre el salón decimonónico ${ }^{4}$. Además de la interpretación de música de cámara, se ha constatado también la práctica sinfónica en ambientes más íntimos no solamente de la capital, sino en otras ciudades españolas con sociedades musicales $^{5}$. Al igual que ocurre con la Sociedad de Conciertos, durante el Sexenio democrático se aprecia un aperturismo al repertorio español también en el salón. La década de los años setenta del siglo XIX es, sin duda, la época en la que se cimienta el repertorio sinfónico decimonónico creado por compositores españoles. En este sentido se aprecia un cambio con respecto al periodo isabelino, debido al renovado gusto del público por la novedad sinfónica, que tiene como respuesta, por parte de los músicos, el surgimiento de más orquestas, así como de más recitales y otras tipologías de conciertos.

En la búsqueda de repertorio sinfónico decimonónico compuesto por músicos españoles encontramos varias partituras conservadas en la Biblioteca

delo de sociedad profesional", Cuadernos de Música Iberoamericana, vols. 8-9, 2001, pp. 125-148. "La disolución de la Sociedad de Conciertos de Madrid y la creación de la Orquesta Sinfónica (1903-1904). Cambios en la infraestructura orquestal madrileña a comienzos del siglo XX", Sulcum sevit: estudios en homenaje a Eloy Benito Ruano, Eloy Benito Ruano (coord.), Oviedo, Universidad de Oviedo, vol. 2, 2004, pp. 939-971.

${ }^{2}$ R. Sobrino: "Catálogo de las obras españolas del Archivo de la Sociedad de Conciertos de Madrid”, Anuario Musical, 45, 1990, pp. 235-296.

${ }^{3}$ La recuperación de este repertorio ha sido realizada fundamentalmente por el Instituto Complutense de Ciencias Musicales (ICCMU), que ha publicado desde los años noventa numerosos títulos del repertorio sinfónico, como se puede ver en su catálogo: www.iccmu.es.

${ }^{4}$ Celsa Alonso: "Los salones: un espacio musical para la enseñanza del XIX", Anuario Musical, 48, 1993, pp. 165-205.

${ }^{5}$ Alberto Hernández Mateos: "Modernización musical y periferia en la España isabelina. Un caso de estudio: La Escuela de San Eloy y la Salamanca de Martín Sánchez Allú", Revista de Musicología, vol. XXXVIII, n. ${ }^{\circ}$ 2, 2015, pp. 465-497; Manuel Morales Muñoz: "Sociedades musicales y cantantes en Andalucía (1843-1913)", Bulletin d'Histoire Contemporaine de l'Espagne, n. ${ }^{\circ} 20$, 1994, pp. 57-66. 
del Real Conservatorio Superior de Música de Madrid que tenían un exlibris desconocido hasta la fecha. El sello, que podemos ver en la ilustración 1, reza "La Filarmónica de Madrid", lo que en primera instancia podría relacionarse con la Orquesta Filarmónica de Madrid que desarrolló su actividad desde principios del siglo XX. Pese a esta primera suposición, los compositores representados en las obras del Conservatorio desarrollaron su actividad musical en el último tercio del siglo XIX, descartando con ello la primera hipótesis.

La investigación que presentamos se centró en

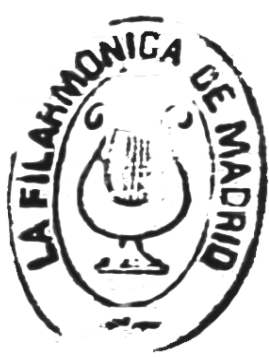

Ilustración 1. Sello de la Filarmónica de Madrid aportar luz acerca de la Filarmónica de Madrid, una institución que no aparece mencionada en la bibliografía y cuya existencia no se conocía hasta ahora. Las principales fuentes para realizar este trabajo fueron las partituras conservadas que nutrieron el repertorio de la agrupación y la prensa de la época. Se desconoce dónde se encuentran los fondos administrativos -si es que los hubo-, aunque se ha localizado un reglamento y un listado de miembros que sirven para comprender las pretensiones de la Filarmónica de Madrid.

\section{Creación de la Filarmónica de Madrid}

El 5 de junio de 1872 se presentó en la capital de España una nueva sociedad musical, bajo el nombre de la Filarmónica de Madrid, con el objetivo de celebrar una serie de conciertos en dicha ciudad ${ }^{6}$. La iniciativa de crear una agrupación filarmónica de pequeño formato partió de los salones del abogado, compositor y pianista Fermín María Álvarez Mediavilla (1833-1898), según atestigua Felipe Pedrell en una remembranza laudatoria que dedica al que fue su amigo ${ }^{7}$. La faceta que desarrolló como mecenas de las artes, en especial de la música, ha transcendido en la historiografia moderna, quedando un vacío en lo que respecta a su faceta de músico, como intérprete y compositor. Poco se sabe de la formación musical que recibió Álvarez, pero esta marcó su afición filarmónica a lo largo de toda su vida. La única información al respecto proviene del mismo artículo mencionado, en el que Pedrell notifica un supuesto viaje a Cuba que le sirvió para entrar en contacto con Louis Moreau Gottschalk, Teresa Carreño, Nicolás Ruiz Espadero y otros notables artistas de la isla. Asentado

\footnotetext{
${ }^{6}$ El Imparcial, Madrid, 5-6-1872, p. 4

${ }^{7}$ Felipe Pedrell: "Remembranzas de Músicos Ampurdaneses, Fermín María Álvarez", Le Veu de l’Empordà, Figueras, 30-1-1915, p. 2. Para profundizar en su figura, C. Alonso: "Álvarez Mediavilla, Fermín María”, Diccionario de la Música Española e Hispanoamericana, SGAE-ICCMU, Madrid, 1999, vol. 1, pp. 373-377.
} 
ya en Madrid, contrajo matrimonio con su álter ego, Eulalia Goicoerretea, una distinguida dama de la aristocracia y diletante como él. La posición social que ambos poseían, a lo que se unía su inclinación por la música, favoreció que pronto se erigieran como referentes en el terreno musical madrileño, tanto por su labor de mecenazgo como por organizar veladas musicales de gran calidad artística. Con estos hechos se ganaron el favor de músicos y críticos contemporáneos, entre los que se encuentra Antonio Peña y Goñi, quien dedicó a Álvarez las siguientes líneas:

Álvarez ha personificado en Madrid el tipo raro y hoy desconocido del filántropo musical. Millonario, hubiera recordado a aquellos célebres magnates alemanes, protectores decididos del arte y los artistas, de los cuales fue ideal el príncipe Sterhazy [sic], el noble digno mecenas de Haydn. [...] Desgraciadamente los millones escasean y aquellos tiempos pasaron. Álvarez, que no es pobre (dicho sea en buena hora) hubo de contentarse con lo que tenía y, en un país donde la música, generalmente hablando, constituye un digestivo más o menos eficaz, $[\ldots]$ tuvo el valor heroico de destinar una parte de su peculio para dar a conocer y propagar nuevos específicos con el objeto de aliviar, si era posible, los estómagos estragados que tanto abundan por estos mundos de Dios y del garbanzo ${ }^{8}$.

A lo largo del siglo XIX los músicos españoles desarrollaron un discurso pesimista en relación con diferentes aspectos tales como el idioma empleado en la ópera, la falta de apoyo institucional, la mala calidad de determinado repertorio y otros alegatos que se reflejan en el texto anterior. No es totalmente cierto que hubiese pocos personajes que fomentaran la práctica musical durante el periodo en el que vivió Álvarez; la profesora Celsa Alonso habla de un panorama bastante intenso en los palacios y casas de nobles como la condesa de Montijo, los duques de Sotomayor, los condes de Velle, el marqués de Villavieja y muchos otros ${ }^{9}$. La comparativa con centros musicales como París y las falsas expectativas que tenían de otros países, planteaba siempre un discurso de protesta y reivindicación, si bien la realidad era que existía una práctica musical muy activa en Madrid.

Lo que sí podemos destacar de la actividad musical de los Álvarez y que la diferenciaría de otras, fue la calidad de los músicos que pasaron por su palacio de la calle de Fuencarral de la que se hizo eco Peña y Goñi:

Álvarez reunió en su casa una sociedad escogidísima, en la cual la aristocracia de la sangre y del talento se daban la mano. Los cantantes más eminentes de nuestro regio coliseo asistían [...]. La orquesta se componía de profesores que se llamaban Romero, Mirecki, Casella, el Marqués de Bogaraya, el Marqués de Martorell y otros no menos distinguidos ${ }^{10}$.

\footnotetext{
${ }^{8}$ F. Pedrell: "Remembranzas...", p. 2.

${ }^{9}$ C. Alonso: La canción lírica española en el siglo XIX, Madrid, ICCMU, 1998, pp. 199-221.

10 Antonio Peña y Goñi: "Bocetos musicales", Crónica de la Música, Madrid, 30-1-1879, p. 1.
} 
El clarinetista Antonio Romero, los violonchelistas Víctor Mirecki, César Casella y Alonso Álvarez de Toledo, marqués de Martorell, o el flautista Gonzalo Saavedra, marqués de Bogaraya, son algunos de los artistas que aparecen en las reseñas de las reuniones musicales que tenían lugar en el hogar de los Álvarez.A esta lista de músicos habría que añadir a Dámaso Zabalza,Antonio Romero, José Tragó, Carlos Beck, Pedro Miguel Marqués, Felipe Pedrell, José Inzenga, José Juan Santesteban y Emilio Serrano, entre otros. La profesionalidad se impuso al aficionado filarmónico que inundaba los salones en el periodo isabelino. Todos ellos fueron intérpretes en noches tan destacadas como la acaecida unos meses antes del estreno de la Filarmónica, como la del 10 de febrero de 1872 por el santo de la señora de la casa, Santa Eulalia, en la que se interpretó El médico a palos, traducción al castellano por Guillermo Lennon Hunt de la ópera cómica de Gounod Le Médecin malgré lui instrumentada por el propio Álvarez ${ }^{11}$.

Fruto de la interacción entre estos músicos y con la ayuda de otros personajes de la cultura y la aristocracia, se fraguó la idea de crear una sociedad filarmónica que saliera de las paredes del palacio de la calle Fuencarral. Con el nombre de la Filarmónica de Madrid y bajo el amparo de la actividad musical que se había desarrollado gracias a Fermín María Álvarez se formó una agrupación liderada, según la prensa, por "el marqués de Bogaraya, el de Martorell, Hunt, el Sr. Quesada (don Adolfo) y otros varios [...] creadores de aquella Sociedad, llamada a prestar grandes servicios al arte" ${ }^{12}$. Estos personajes del siglo XIX tenían una pasión común: la música; sus circunstancias, trabajos y títulos les permitieron un acercamiento a la música que iba mucho más allá del amateurismo.

\section{El reglamento, fundamento de la sociedad}

Con intención de ser una sociedad sólida y duradera -aunque no lo lograrían- se encargaron de redactar un reglamento y una lista de sus integrantes (Apéndices 1 y 2, respectivamente). En el primero de los documentos - cuyo único ejemplar localizado perteneció a José Inzenga y se encuentra en la Biblioteca Nacional de España- encontramos las bases y objetivos de la Filarmónica de Madrid. Su principal preocupación fue "fomentar el arte musical, celebrando academias para sus ensayos, verificando cuantos conciertos permita el estado de sus fondos"13. Este propósito era compartido por otras agrupaciones como la Sociedad de Conciertos, cuya función era la de dar conciertos por cuenta propia.

\footnotetext{
${ }^{11}$ La Época, Madrid, 8-2-1872, p. 3.

12 Ibid., Madrid, 10-6-1872, p. 3.

${ }^{13}$ Madrid, Biblioteca Nacional de España, M.FOLL/100/10.
} 
A diferencia de la Sociedad de Conciertos, la Filarmónica no estableció en el reglamento la creación de un fondo social para sus miembros, posiblemente al considerar que gran parte de los participantes colaboraban más por placer que por dinero. Esta hipótesis se ve respaldada con los títulos nobiliarios de sus fundadores, los cuales reflejan una posición social bastante elevada y cargos de relevancia. Gonzalo Saavedra (1831-1899), marqués de Bogaraya, tuvo un papel importante en política, llegando a ser gobernador, alcalde y presidente de la Diputación Provincial de Madrid. Alonso Álvarez de Toledo (18351895), marqués de Martorell, desempeñó su carrera en el ejército. Adolfo de Quesada, conde de san Rafael de Luyanó, según indica Ana Vega Toscano, tenía una posición desahogada, siendo además un destacado pianista de su generación ${ }^{14}$. Como indicábamos con anterioridad, cada uno de ellos tocaba un instrumento de manera profesional, lo que llevó al marqués de Bogaraya a solicitar una plaza de flauta honorífica de la Real Capilla: "Las condiciones y aptitud del solicitante son suficientes para el buen desempeño de un destino al que solo aspira por sus aficiones artísticas, con renuncia absoluta a todo sueldo, retribución ni vacantes de número que ocurran en su clase" ${ }_{15}$. Zubiaurre, maestro de la Real Capilla, pone de manifiesto el desinterés del marqués por recibir un sueldo como flautista. Tocar por placer podría definir la creación de la Filarmónica de Madrid.

La sociedad estaba regida por una junta directiva, formada por un presidente, un tesorero, un contador, dos secretarios, un archivero y tres vocales, siendo la distribución de cargos la siguiente:

$\begin{array}{ll}\text { Presidente: } & \text { Marqués de Bogaraya (Gonzalo Saavedra) } \\ \text { Tesorero: } & \text { Marqués de Martorell (Alonso Álvarez de Toledo) } \\ \text { Contador: } & \text { Francisco Gerner } \\ \text { Archivero: } & \text { Manuel Fernández Hidalgo } \\ \text { Secretarios: } & \begin{array}{l}\text { Ernesto Creus } \\ \text { Mariano Ahumada }\end{array} \\ \text { Vocales: } & \begin{array}{l}\text { Conde de Peña de Ramiro } \\ \text { Baldomero Monet } \\ \text { (Sin elegir) }\end{array}\end{array}$

En el reglamento aparece reflejada la obligación de todos los miembros de pagar cuarenta reales en el momento de su inscripción para cubrir los gastos de su actividad, sobre todo lo referente al alquiler del local de ensayos y de conciertos. Los miembros se dividían en socios de número, miembros de mérito y socios honorarios. A su vez, los socios de número podían

\footnotetext{
${ }^{14}$ Ana M. Vega Toscano: "La obra para piano de Adolfo de Quesada, conde de san Rafael de Luyanó", Revista de Musicología, vol. XIV, n. ${ }^{\circ}$ 1, 1991, pp. 249-257.

15 Joaquín Jericó: "Flauta romántica en España", programa de conciertos en la Fundación Juan March, abril-mayo 2001.
} 
ser activos y pasivos. Los activos eran aquellos que participaban en los conciertos y ensayos, con su voz o tocando -debían pagar ocho reales al mes-; los pasivos eran principalmente grandes melómanos que ayudaban a la sociedad -pagaban veinte reales al mes-. Miembros de mérito eran aquellos profesionales que, aunque no llegaban a ser llamados honorarios, demostraban un gran saber en su materia. Por otro lado, estaban los honorarios, entre los que encontramos a Emilio Arrieta, Francisco Asenjo Barbieri, Manuel Fernández Caballero, Hilarión Eslava, Juan Guelbenzu, José Inzenga, Jesús de Monasterio, Dámaso Zabalza y así hasta un total de cincuenta y cuatro miembros ${ }^{16}$. No sabemos si todos ellos tuvieron realmente contacto alguna vez con la sociedad, ya que como se puede leer en una crítica de $L a$ Época sobre el primer concierto, se pone de manifiesto la ausencia de "ilustres músicos" a los que, teóricamente, habían hecho socios honorarios ${ }^{17}$.

\section{Espacio pequeño y público selecto}

El lugar elegido para realizar los ensayos y los conciertos fue el salón pequeño de la Escuela Nacional de Música, también denominado Conservatorio, que en aquella época se ubicaba en el Teatro Real. La Filarmónica no dispuso de otro local donde ensayar, pues el ansiado salón grande del mismo emplazamiento no estaba disponible tras el incendio que tuvo lugar en 1867. El Conservatorio de Madrid se estableció como un espacio de difusión de la música del momento, al facilitar sus salas para la celebración de conciertos tanto sinfónicos como de cámara, al igual que estaban haciendo otros conservatorios europeos. La Escuela Nacional de Música era sede estable de la Sociedad de Cuartetos y de eventuales conciertos organizados principalmente por profesores del centro, por lo que la Filarmónica compartió el salón pequeño en beneficio de la actividad musical realizada en este centro público.

El tamaño de la sala condicionó el límite de asistentes, no pudiendo dar cabida a la demanda de público que quería escuchar a la Filarmónica.Aunque al principio los oyentes no eran muy numerosos, en la apertura del año 1873 se incrementó su número, teniendo que quedarse los que no cabían en el salón en una sala contigua para al menos poder escuchar el concierto $^{18}$. Debido a la corta vida de la entidad, el problema del local de ensayos no llego a solucionarse, ya que el gran salón de la Escuela Nacional de Música y Declamación no se inauguró hasta 1878, cuatro años después de su desaparición.

\footnotetext{
${ }^{16}$ Madrid, Biblioteca Nacional de España, M.FOLL/111/10.

${ }^{17}$ La Época, Madrid, 10-6-1872, p. 3

${ }^{18}$ La Moda Elegante, Madrid, 22-3-1873, p. 6.
} 
Otras conocidas salas de la capital a finales de siglo, como las de Benito Zozaya (1883) o Antonio Romero (1884), debieron de esperar unos años para ofrecer una alternativa a la del Conservatorio, la cual, según Romero, era de dificil acceso por los problemas de burocracia que requería para su uso $^{19}$. Hay que tener en cuenta que, por ejemplo, la de Zozaya "aunque linda, [era] insuficiente para albergar los acontecimientos que Madrid" requería, por lo que vemos la relación que existe entre espacio y agrupaciones, condicionando el repertorio y la forma de ejecutarlo. Como comentaremos a continuación, el repertorio característico de la Filarmónica encontró en la Escuela Nacional un lugar adecuado para su ejecución, mientras que en otro emplazamiento podía haberse enfrentado a problemas de amplitud. El espacio determinó los arreglos que los miembros de la sociedad tuvieron que hacer de las obras con una plantilla más numerosa, así como los requerimientos que los compositores que hicieron piezas ex proceso tuvieron que tener en consideración.

Si una parte de los fundadores eran nobles, no debemos extrañarnos de que un porcentaje del público fuera de la misma categoría social que aquellos. Son numerosas las críticas en la prensa que hacen hincapié en quiénes asistían a estos conciertos, siendo en algunas ocasiones las líneas dedicadas a este respecto más numerosas que las destinadas a comentar la propia música:

El salón pequeño del Conservatorio apenas bastaba a contener la escogida y numerosa concurrencia que allí se había congregado, compuesta de muchas bellas damas y hombres muy conocidos de la buena sociedad. Entre las primeras recordamos a las señoras y señoritas de Suárez, Estéfani, Roldán, Rey, Escobar, Mosquera, Ami, Bassencourt, Palomino de Guzmán, Abella, Corera, Gamir, Cabrero de Ahumada, Gozalvo, la célebre pianista María Martín y otras más que no recordamos en este momento. El sexo fuerte estaba representado dignamente por los señores conde de Bélgica, marqués de Monistrol, Mosquera (hijo), Navarrete, Moné, Tragó, hijo del marqués de Bendaña, Tamarit, representante del Brasil y otros varios individuos del cuerpo diplomático extranjero, y muchas más personas que no mencionamos por no alargar demasiado esta ligera revista ${ }^{20}$.

El público estaba conformado principalmente por nobles adscritos a la política, altos cargos y militares destacados, también vinculados al poder, lo que no variaba mucho del público que asistía a los palacios en épocas anteriores. Por ejemplo, sabemos que Daniel Sickles, militar y miembro del cuerpo diplomático de Estados Unidos en España, era socio de la Filarmónica y debió asistir a sus conciertos. El marqués de Medina Sidonia, José Álvarez de Toledo y Silva o el vizconde de Manzanera, Isidoro de Hoyos y

\footnotetext{
${ }^{19}$ La Ilustración Española y Americana, Madrid, 8-5-1884, p. 3.

${ }^{20}$ La Iberia, Madrid, 27-3-1874, p. 3. En el Apéndice 2 se puede apreciar el tipo de público que asistía a los conciertos con los nombres que aparecen en los socios pasivos.
} 
Rubín de Celis, los cuales desempeñaron cargos en el Senado, fueron público de los conciertos. Las relaciones entre los miembros de la élite social giraron en torno a la Filarmónica de Madrid, consiguiendo con los conciertos programados instituir el salón pequeño del Conservatorio como un espacio de sociabilización.

No debemos olvidarnos de las mujeres de todas estas autoridades y de las esposas de los integrantes de la Filarmónica, pues conformaron también parte del público y desempeñaban un papel importante en este tipo de eventos. El trato que recibían era bastante diferente en comparación con las libertades de protocolo de los hombres. Dos artículos del Reglamento de la sociedad se centran en el papel de la mujer. Por un lado, según el artículo 29, se contaba con una comisión de etiqueta, que además de vigilar que no entrara ninguna persona sin entrada, tenía la obligación de colocar a las señoras en el salón. Por otro lado, el artículo 32 manifiesta las limitaciones que tenía la mujer en el siglo XIX. Bajo ningún concepto podía asistir en solitario ninguna socia, por lo que se debía dar una entrada a su acompañante, el cual debía ser pariente inmediato. La consanguinidad con una dama o el pago como socio eran las únicas formas de poder escuchar a la sociedad, tal y como se sobreentiende en esta frase escrita para solventar un problema con las entradas de uno de los conciertos:"se ruega a los señores socios que por una equivocación involuntaria no hubiesen recibido sus billetes, los reclamen en la secretaría, calle de Sta. Catalina número 8"

La Filarmónica de Madrid llevaba a cabo sus conciertos con un público privado, pero en un sitio del Estado. La Escuela Nacional de Música, pese a ser un ente público, favoreció las actividades de carácter particular en su beneficio, pues el alquiler en este caso del salón pequeño proporcionaba ingresos a la institución. Los términos público y privado caminaron de la mano con la sociedad; ejemplo de ello lo encontramos en una crítica realizada sobre la interpretación de Gallia de Gounod por la orquesta y el coro del Teatro Real en que se lee: "Esta noche se verificará el segundo concierto sacro, que será sin duda el más notable de la temporada, por ejecutarse por primera vez ante el público de Madrid la Gallia de Gounod [...] se ejecutó el año pasado en el salón del Conservatorio, merced a La Filarmónica de Madrid"22. La obra fue estrenada en Madrid el 28 de abril de ese mismo año 1873 por la Filarmónica -no en 1872 como dice la crítica-, dos años después de su composición y estreno en Londres ${ }^{23}$. Según la crítica hubo dos tipos de público en sendos conciertos: los que asistieron por ser socios o invitados de la Filarmónica y el público madrileño que pudo permitirse pagar una entrada para el Teatro Real. En ambos casos

${ }^{21}$ La Correspondencia de España, Madrid, 23-12-1873, p. 1.

22 El Imparcial, Madrid, 13-3-1874, p. 3. 
el emplazamiento en que tuvieron lugar las dos audiciones determinó quién podía tener acceso a su escucha, un público con un nivel social alto capaz de pagar la cuota o la entrada. A diferencia de la Sociedad de Conciertos que promovió la música intentando llegar a un espectro social más amplio -sobre todo con los conciertos de verano en los Jardines del Buen Retiro-, la Filarmónica pudo ser disfrutada por muy pocas personas. El "público madrileño" de la crítica se refiere a este reducido grupo y no a toda la población de la capital española. La difusión de noticias en prensa no conllevaba una invitación a participar en los eventos, sino a plasmar, en muchos casos, lo que solo unos elegidos podían disfrutar.

\section{Breve historia de un sueño, desaparición}

Pese a la importancia que alcanzaron los conciertos de la Filarmónica, con el incremento del público y calidad de la agrupación, la sociedad desapareció en junio de 1874, cuando se cumplían dos años de su creación. Este final supuso una contradicción con las tendencias generales de la actividad musical de las élites. Si durante la Primera Republica los conciertos organizados por la oligarquía se habían visto reducidos, con la Restauración borbónica liderada por Alfonso XII los salones se abrieron otra vez para las élites, además de verse incrementados los eventos musicales, tales como los bailes de máscaras, las funciones teatrales y los conciertos públicos. La Filarmónica nació, vivió y murió en un periodo convulso para la mayoría de los integrantes de la sociedad, por lo que hay que celebrar la existencia de un bastión de tal calado para la música.

Las circunstancias de este hecho no están claras, pues en la prensa -única fuente que tenemos hasta la fecha- no aparece alusión específica al tema. Una posible hipótesis se puede deducir de la semblanza que realiza Peña y Goñi de Fermín María Álvarez, donde acota la celebración de eventos musicales en su casa desde 1866 hasta 1874, el mismo año en que desaparece la agrupación ${ }^{24}$. Por otro lado, según narra el marqués de Alta Villa: “Al perder a la compañera de su alma, sellando con el luto sus salones, Álvarez se dedicó a la composición musical con toda su energía, a fin de llenar su corazón de otros afectos que en nada causaron celos a los que había perdido"25. Fruto de estos datos se puede plantear como hipótesis que la decisión de finalizar la actividad musical en casa de los Álvarez tras la muerte de Eulalia, se vio extrapolada a la que realizaba la Filarmónica de Madrid en el Conservatorio por el papel que tuvo el matrimonio en la creación y posterior desarrollo de la

\footnotetext{
${ }^{23}$ La Época, Madrid, 1-4-1873, p. 4.

${ }^{24}$ A. Peña y Goñi: "Bocetos...", p. 1.

25 Marqués de Alta Villa: "Fermín M. Álvarez", La Correspondencia de España, Madrid, 14-9-1898, p. 1.
} 
agrupación. Pese a su desaparición, la actividad en la Escuela de Música y Declamación continuó con la participación de algunos de los miembros de la ya extinta Filarmónica de Madrid que tenían vinculación con el centro, pero en modalidades de pequeño formato.

\section{El repertorio de los conciertos}

En los dos años que duró la Filarmónica de Madrid se organizaron casi una veintena de conciertos divididos en dos temporadas (Apéndice 3). La primera de ellas empezó el 5 de junio de 1872, lo que implicó que este impulso inicial se viera truncado por el estío, no retomando de nuevo la actividad hasta noviembre de ese mismo año. La temporada tuvo un total de doce conciertos que acabaron el mismo día y mes que comenzaron, pero de 1873. La segunda temporada dio comienzo en octubre de 1873, habiendo tenido de descanso todo el verano, meses en los que las élites viajaban a sus casas del norte y algunos músicos realizaban giras por provincias. La temporada se vio mermada por la desaparición de la agrupación, realizándose solamente siete conciertos que concluyeron con el celebrado el 2 de junio de 1874. Aunque no había una fecha fija para la realización de los eventos, habitualmente tenían lugar una vez al mes, tiempo que les permitía ensayar repertorio nuevo para su público.

Los conciertos se dividían en dos partes, como puede verse en el siguiente programa extraído de un anuncio de la prensa:

PRIMERA PARTE

1. ${ }^{\circ}$ Overtura de Il poeta in campagna, con la instrumentación tal como la escribió el autor el año de 1767, Guglielmi.

2. ${ }^{\circ}$ La serenata, melodía arreglada para flautín y ejecutada por el niño Francisco González, Schubert.

3. Aria de La Traviata, por la señorita doña Adela Cristóbal Portas, Verdi.

4. ${ }^{\circ}$ Primer concierto para violín con acompañamiento de orquesta, por el Sr. Espino, Bériot.

5. Fantasía sobre motivos de Guillermo Tell, Broca.

\section{SEGUNDA PARTE}

1. ${ }^{\circ}$ La ausencia, melodía moruna compuesta expresamente para la sociedad, Espino.

2. ${ }^{\circ}$ Fantasía sobre motivos de Lucrecia Borgia, para piano con acompañamiento de orquesta, por el Sr. Zabalza, Mata.

3. ${ }^{\circ}$ Melancolía, romanza con acompañamiento de orquesta, por la señora doña Elisa Luján de Torres, Zubiaurre.

4. ${ }^{\circ}$ Trío para flauta, violín y violoncello, con acompañamiento de piano por los señores marqueses de Bogaraya y Martorell, y los Sres. Espino y Berk [y] Michelis.

5. Overtura de Elisa e Claudio, Mercadante ${ }^{26}$.

\footnotetext{
${ }^{26}$ La Época, Madrid, 25-2-1873, p. 4.
} 
La elección de este concierto no es arbitraria, pues resume muy bien el tipo de repertorio que se hacía en el salón pequeño del Conservatorio. La primera clasificación que podemos establecer está determinada por las agrupaciones empleadas: grupos de cámara por un lado y orquesta por otro. Esta tipología de concierto misceláneo la encontramos ya desde finales del siglo XVIII y gracias a la Filarmónica podemos seguir documentándola un siglo después. Es difícil localizar más referencias a esta dualidad en el Madrid de los setenta, pues por un lado encontramos conciertos monográficos de música de cámara en los salones privados o en el mismo Conservatorio con la Sociedad de Cuartetos y los conciertos de profesores y alumnos; y por otro lado los conciertos sinfónicos de la Sociedad de Conciertos o los conciertos vocales-instrumentales interpretados en los teatros en beneficio de un determinado artista.

Dentro del repertorio para las agrupaciones de cámara hay una gran variedad de obras que van desde las destinadas a un solo instrumento hasta el sexteto. Las piezas para un único intérprete estaban destinadas prácticamente al piano y podemos poner como referencias una balada de Chopin que tocó Isabel Echevarría, o la Gran polonesa op. 22 del mismo compositor ejecutada por Tragó. Aumentando el número de músicos están presentes obras de Ludwig van Beethoven, Robert Schumann, Anton Rubinstein, Stanislas Verroust y Nicolás Ruiz Espadero, entre otros. Por poner un ejemplo, se tocó el Cuarteto con piano en Mi bemol, op. 16 de Beethoven, un Trío para piano, violín y violonchelo de Rubinstein, un Cuarteto para flauta, violín, violonchelo y piano de Vincenzo de Michelis. La elección de este tipo de repertorio extranjero debió de satisfacer a los críticos, pues eran numerosas las sátiras que se hacían a la mala calidad de las piezas y al exceso de variaciones y fantasías que nutrían los programas. Pese a todo, este tipo de obras tan de moda y criticadas estuvieron también presentes en la Filarmónica con títulos como la Fantasía para violín y piano sobre motivos de la ópera Guillermo Tell que interpretaron Casimiro Espino al violín y Zabalza al piano, o la misma obra para orquesta adaptada por Enrique Broca. Otro ejemplo sería Trémolo, aire variado para flauta del compositor francés Jules Demersmann, interpretada por el marqués de Bogaraya.

Los encargados de tocar estas piezas eran casi siempre los mismos, entre los que se encontraban los fundadores: el marqués de Bogaraya, el de Martorell y músicos profesionales como el violinista Casimiro Espino, el violonchelista franco-prusiano asentado en Madrid Víctor Mirecki así como el pianista Carl Beck, todos ellos grandes músicos del momento. Mención especial merece el pianista Adolfo de Quesada quien fue adalid de su amigo, el compositor residente en Cuba, Nicolás Ruiz Espadero. Junto con Mirecki interpretó un dúo para violonchelo y piano que posiblemente fuera la primera vez que se escuchaba fuera de la isla. 
El elemento vocal desempeñó un papel importante dentro de la Filarmónica, tanto en formato de cámara como con orquesta. Encontramos arias, dúos y demás agrupaciones de compositores como Vincenzo Bellini, Giuseppe Verdi y Saverio Mercadante, principalmente. Los músicos italianos fueron los más interpretados, seguidos de los franceses, cuyo máximo exponente fue Charles Gounod, posiblemente escogido por la devoción que sentía Álvarez por su música. Este tipo de obras fueron cantadas por integrantes de la misma sociedad, como eran Adela Cristóbal Portas, Elisa Luxán de Torres, María Mantilla, Isabel Linarro, Lorinda Gamir o Ernestina Espín Colbrand. La preferencia de cantantes femeninas es evidente al analizar los programas y, con respecto a su interpretación, poco se puede extraer de la prensa, ya que todas fueron maravillosas a oídos de los aduladores críticos. Aunque la mayoría de las obras eran para solistas, la sociedad contaba en algunas ocasiones con sus integrantes femeninas para algunos coros de óperas como el de Sacerdotisas de Orazi e Curiazi de Mercadante. Las obras vocales en castellano se limitan a una única pieza titulada La melancolía, romanza con orquesta de Valentín Zubiaurre. Este hecho se puede entender extrapolándolo al gusto que tenía la aristocracia por el teatro lírico, pues era más frecuente verles en el Teatro Real escuchando ópera en italiano, ya fuera de compositor español o extranjero, que apareciendo por el Teatro de la Zarzuela u otro de mismas características donde el castellano estaba presente en romanzas y otros formatos.

Dentro de las composiciones puramente sinfónicas caben destacar las oberturas de óperas de compositores como Rossini, Mercadante y Gounod, tanto por su presencia constante, como por el rol que adquirieron de presentación y despedida en los conciertos de la Filarmónica, sobre todo en la segunda temporada. También se tocaron movimientos sueltos de un par de conciertos para piano de Mendelssohn y de Ferdinand Ries, así como el Concierto $n .^{\circ} 1$ para violín y orquesta de Charles-Auguste de Bériot completo. Mención especial merece la interpretación del Concierto para piano y orquesta de Soledad Bengoechea, dedicado como reza en la partitura a quien lo interpretó, "Charles Beck" ${ }^{27}$. La denominación "concierto" utilizada por la prensa no es la más apropiada para referirse a esta obra. La propia compositora escribió en la portada del manuscrito autógrafo "Solo de Concert pour le Piano avec ac[c]ompagnement d'Orchestre", etiqueta más adecuada para una composición virtuosística para piano y orquesta de escasa duración. Este tipo de repertorio no llamó mucho la atención del público madrileño y de hecho se ve como el género concierto se cultivó muy poco por los compositores españoles del siglo XIX. Sin embargo, hay que des-

\footnotetext{
${ }^{27}$ Dedicatoria "Ofrece este insignificante recuerdo al señor don Juan María Guelbenzu su admiradora [Firma]Soledad de Bengoechea", Madrid, Biblioteca Nacional de España, M.GUELBENZU/1485.
} 
tacar el intento que llevó a cabo la agrupación al programar estas obras en su corta vida, lo que podía haber favorecido su permanencia en los conciertos si hubiera sobrevivido más allá de 1874. Lo mismo pasó con la sinfonía, cuyo género apenas se vislumbró de no ser por el segundo movimiento de la Sinfonía $n .^{\circ} 2$ de Beethoven. La melodía para orquesta presente gracias a Valverde, Bengoechea y Espino, pone de manifiesto la relación que existía entre la música francesa y la española en los años setenta. El género que se modificó desde la mélodie para piano y voz hasta la obra breve e íntima para orquesta, fue trabajada no solo en la Filarmónica, sino también en la Sociedad de Conciertos y posteriormente en la Unión Artístico Musical28. Este hecho hace notorio la predilección por este tipo de obra más que por sinfonías, conciertos o poemas orquestales, géneros todos ellos de gran demanda y gusto en Europa central, pero que en España tardaron en imponerse en favor de otras obras.

El repertorio de la Filarmónica se vislumbra como un híbrido entre lo descrito por la profesora Celsa Alonso para el salón y el repertorio sinfónico coetáneo expuesto por Ramón Sobrino ${ }^{29}$. Cuando los conciertos de los salones de los Álvarez salen hacia el Conservatorio, llevan consigo parte de su repertorio al que añaden la participación del elemento sinfónico. De entre todo este repertorio cabe destacar el interés que suscitan las composiciones creadas por autores españoles para la Filarmónica de Madrid, tanto originales como las adaptaciones y orquestaciones de obras ya existentes. Gracias a la existencia de esta sociedad el repertorio sinfónico de compositores españoles se enriqueció con:

1. Obras de nueva creación

Obertura capricho, Fermín María Álvarez

Melodía para violín, Genevieve, melodía para orquesta, y Solo de concierto para piano y orquesta, Soledad Bengoechea.

Andante melódico para orquesta, Enrique Broca

Polonesa para orquesta, La ausencia, melodía moruna, y La mendicante, melodía para orquesta, Casimiro Espino ${ }^{30}$

Preludio nell'opera Il segreto, José Inzenga

Angélica, melodía para orquesta, Joaquín Valverde

${ }^{28}$ M. Á. Ríos: "Casimiro Espino (1845-1888): las melodías para orquesta, un canto sin palabras", trabajo fin de carrera tutorizado por Enrique Igoa, Real Conservatorio Superior de Música de Madrid, 2015 (inédito).

${ }^{29}$ C. Alonso: "Los salones..."; R. Sobrino: "La música sinfónica en el siglo XIX", La música española en el siglo XIX, Emilio Casares y Celsa Alonso (eds.), Universidad de Oviedo, 1995, pp. 317-322; id.: "Los salones: un espacio musical para la enseñanza del XIX", Anuario Musical, 48, 1993, pp. 165-205.

${ }^{30}$ La mendicante ha sido interpretada por la Orquesta Sinfónica de la Universidad Complutense de Madrid, bajo la dirección de José Sanchís en el Anfiteatro Ramón y Cajal de la Facultad de Medicina de la misma universidad, el 30 de mayo de 2017, a partir de nuestra edición crítica. 
2. Arreglos nuevos para la agrupación

Obertura de Le Médecin malgré lui de Gounod, Les adieux e l'estranger, melodías de Rosenhaim, Melodía para orquesta de Schumann, Obertura de Isabella d'Aragon y Berceuse del propio orquestador, Fermín María Álvarez

La carità de Rossini, arreglada para quinteto de cuerda, Miguel Benavent

Fantasía para orquesta sobre motivos de la ópera Robert le Diable y Fantasía característica para violonchelo sobre motivos de la ópera Roberto le diable de Serrais, Enrique Broca

Le Sogne de F. David, y Mira la blanca luna, dúo de Rossini arreglado para violín, violonchelo y piano, Casimiro Espino

Fantasía para sexteto sobre motivos de Les Huguenots, Mariano Vázquez La melancolía, romanza con orquesta de Valentín Zubiaurre, el propio autor.

3. Existen además cuatro composiciones que, por falta de información, no sabemos si fueron compuestas para la agrupación, fueron estrenadas por la Filarmónica o, simplemente, arregladas para esta:

Fantasía sobre motivos de Lucrezia Borgia para piano y orquesta, Manuel de la Mata

Fantasía para cornetín, Nicari

Fantasía para orquesta sobre motivos de la ópera Otello, Francisco González.

Sexteto para cuerda y piano, Pedro Miguel Marqués.

\section{La orquesta}

Del total de 227 socios solo una minoría formaba parte de la orquesta encargada de dar los conciertos. Únicamente tenemos referencias del primer concierto, en el que, según la prensa, la orquesta estaba formada por unos veinte músicos ${ }^{31}$. A diferencia de la Sociedad de Conciertos, cuya orquesta estaba formada por unos 95 intérpretes, el número de integrantes de la Filarmónica de Madrid no estaba fijado en el reglamento. Hemos de suponer que con el paso del tiempo y la acrecentada fama de los conciertos la orquesta pudo verse incrementada, pero las dimensiones de la sala condicionaron el número de músicos. Para saber cómo era la orquesta tomaremos como referencia las obras de compositores españoles de las que se han localizado las partituras, todas ellas en la Biblioteca del Real Conser-

${ }^{31}$ La Época, Madrid, 10-6-1872, p. 3. 
vatorio Superior de Música de Madrid. Se conservan La Ausencia y La Mendicante, dos melodías de Casimiro Espino, Genevieve otra melodía de Soledad Bengoechea, Obertura-capricho de Fermín María Álvarez y Preludio nell'opera "Il segreto" de José Inzenga ${ }^{32}$.

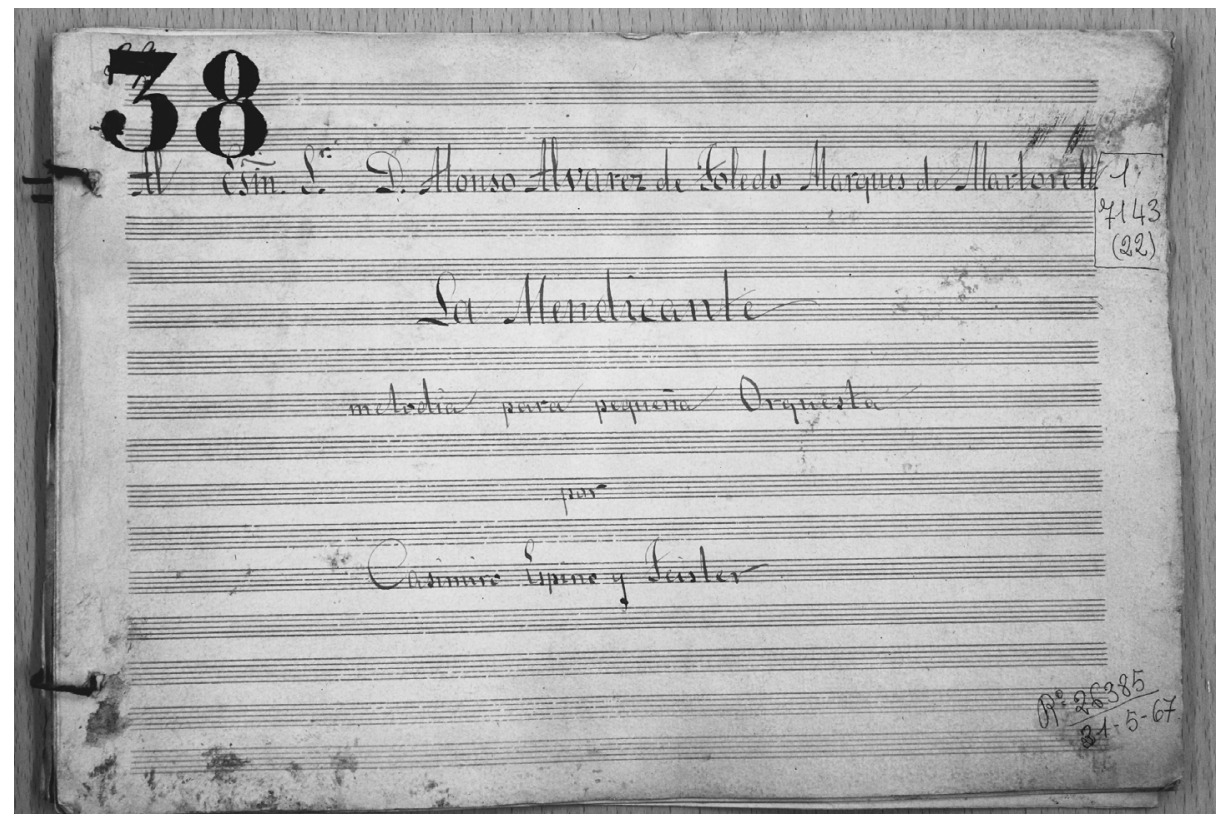

Ilustración 2. Casimiro Espino: La Mendicante melodía. Portada

(Biblioteca del Real Conservatorio Superior de Música de Madrid, 1/7143(22))

Centrándonos en primer lugar en los instrumentos de viento (tabla 1), no hay una estandarización en el empleo de maderas a dos o a uno, esto se debe posiblemente a que las obras estaban compuestas según el número de músicos que tenían en cada momento. Se aprecia un aumento de los vientos, pues si comparamos la Obertura-capricho interpretada el 12 de noviembre de 1872, con La Mendicante estrenada el 2 de marzo de 1874, se observa que casi todos son a dos en esta última, en vez de a uno como en la primera. Aunque no eran recurrentes, en algunas obras estaban presentes el arpa y el piano, los cuales no debieron de estar ni tan siquiera duplicados.

32 Madrid, Biblioteca del Real Conservatorio Superior de Música de Madrid, La Ausencia 1/3485; La Mendicante 1/7143(22); Genevieve 1/15458; Obertura-capricho 1/14299; Preludio nell'opera "Il segreto" $1 / 9777(9)$. 
Tabla 1. Orgánico de vientos, arpa y piano de las partituras

\begin{tabular}{|c|c|c|c|c|c|c|c|c|c|}
\hline & $\underset{\text { 壱 }}{\stackrel{\Xi}{\Xi}}$ & $\begin{array}{l}\stackrel{\widetilde{U}}{\Xi} \\
\text { 荧 }\end{array}$ & $\begin{array}{l}\ddot{0} \\
: 0\end{array}$ & 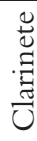 & $\begin{array}{l}\overrightarrow{0} \\
\text { 总 } \\
\text { ⿷匚 }\end{array}$ & 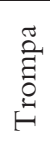 &  & $\underset{\Xi}{\stackrel{\Xi}{\Xi}}$ & $\stackrel{\tilde{2}}{2}$ \\
\hline Obertura-capricho & 1 & 1 & 1 & 1 & 1 & - & 1 & 1 & - \\
\hline Il segreto & 1 & 2 & 1 & 1 & 1 & 2 & 1 & - & - \\
\hline La ausencia & - & 1 & 1 & 2 & 1 & 2 & 2 & - & 1 \\
\hline Genevieve & - & 1 & 1 & 2 & 1 & 2 & 1 & - & 1 \\
\hline La mendicante & & 2 & 2 & 2 & 1 & 2 & 2 & - & - \\
\hline
\end{tabular}

Por lo general, consideramos que debido al lugar de los conciertos, solo había un músico por parte para los vientos. Sin embargo, para determinar el número de instrumentistas de cuerda que conformaban la agrupación, tendremos que especular con las particellas conservadas, tal como observamos en la tabla 2. Tomemos como primer ejemplo Il segreto que fue interpretada el primer año de la Filarmónica: si cada papel de violín era tocado por dos músicos, la familia de cuerda rondaría los doce músicos; si a estos les sumamos ocho vientos - sin incluir el flautín-, estaríamos hablando de una orquesta de veinte músicos, concordando este dato con lo que relataba la crítica del primer concierto. Posteriormente, la orquesta aumentó ligeramente y este hecho se puede constatar observando las fuentes conservadas de La mendicante, que fue programada antes de la desaparición de la Filarmónica. Si tocaban dos violines por atril, como en el caso anterior, la cuerda contaría con dieciséis músicos, a los que sumando once vientos se obtendría una orquesta de veintisiete músicos, que podría llegar a la treintena si hubiese algún músico más duplicando. Esta pequeña agrupación que rondó casi la treintena de músicos es la que se presentó en cerca de veinte conciertos bajo la batuta de músicos como Valentín de Zubiaurre, único referente en prensa a la dirección de la agrupación.

Tabla 2. Número de particellas conservadas

\begin{tabular}{|c|c|c|c|c|c|}
\hline & $\begin{array}{l}\stackrel{\circ}{7} \\
\stackrel{\Xi}{0} \\
\stackrel{5}{\circ}\end{array}$ & $\begin{array}{l}\stackrel{\circ}{i} \\
: \\
\stackrel{7}{9}\end{array}$ & $\begin{array}{l}\frac{\pi}{0} \\
\stackrel{5}{>}\end{array}$ &  & 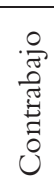 \\
\hline Il segreto & 2 & 2 & 1 & 2 & 1 \\
\hline La ausencia & 3 & 2 & 1 & 2 & 1 \\
\hline Genevieve & 3 & 3 & 1 & 2 & 3 \\
\hline La mendicante & 3 & 3 & 1 & 2 & 1 \\
\hline
\end{tabular}




\section{Relaciones entre obra e intérprete}

Como ya se adelantaba, las obras conservadas fueron compuestas ex profeso para la agrupación. Este hecho hace que podamos encontrar relaciones directas entre el compositor, la obra y el intérprete. La observación del manuscrito de la melodía de Soledad Bengoechea pone en evidencia este hecho, al ver la modificación que sufrió el papel de flauta. Existen dos versiones de una cadencia que enlaza la introducción con el tema principal que podemos ver en el ejemplo 1. La cadencia I es la que aparece pegada en la particella de flauta, mientras que la cadencia II se encuentra en la partitura general autógrafa de Bengoechea. Podemos pensar que, ya que la obra fue compuesta para la Filarmónica, la cadencia I es una alternativa creada por quien desempeñaba el papel de flautista, cuyo compromiso recaía en el marqués de Bogaraya. No podemos afirmar que la sustitución de un pasaje por otro hubiera sido para facilitar o complicar los mismos, ya que dependerían de la forma en que el marqués hubiese interpretado cada uno, sobre todo en el tempo, y la inclusión de accelerandos y ritardandos. Lo que sí parece evidente es que este momento cadencial serviría al solista para mostrar sus cualidades musicales y captar la atención de un público afín que asistía por su vinculación a los miembros de la Filarmónica.

Parece lógico plantear que el repertorio de compositores españoles que se tocó fue compuesto sabiendo quiénes iban a interpretar cada papel, por lo que la dificultad de cada uno radica en las habilidades de esos músicos. En general, no son obras de gran virtuosismo, la complejidad residía en la manera de interpretarlas, requiriéndose para ello un grado de concentración máximo para demostrar un buen nivel de técnica, una buena afinación y un esmero considerable a la hora de las entradas, sobre todo para los vientos. Hay que tener en cuenta que algunos de los músicos de la Sociedad de Conciertos tocaban en la Filarmónica, por lo que no podemos pensar que, aunque las obras de Bengoechea, Álvarez y demás compositores estaban pensadas para una orquesta reducida, eran de peor calidad que otras pensadas para 93 músicos.

El caso concreto de Casimiro Espino viene a confirmar lo anteriormente dicho, pues fue violinista y compositor de ambas agrupaciones, contribuyendo a aumentar el repertorio sinfónico español en ese periodo. Aunque en las dos composiciones que han sobrevivido, La ausencia y $\mathrm{La}$ mendicante, no encontramos pasajes cadenciales específicos, el comienzo de la primera de estas dos melodías para orquesta otorga gran protagonismo a la flauta, junto con el oboe al unísono y el arpa (ejemplo 2). Lo que parece más claro es su participación como concertino en la orquesta, interpretando el solo para violín en la Obertura-capricho de Álvarez. Si Bogaraya era 


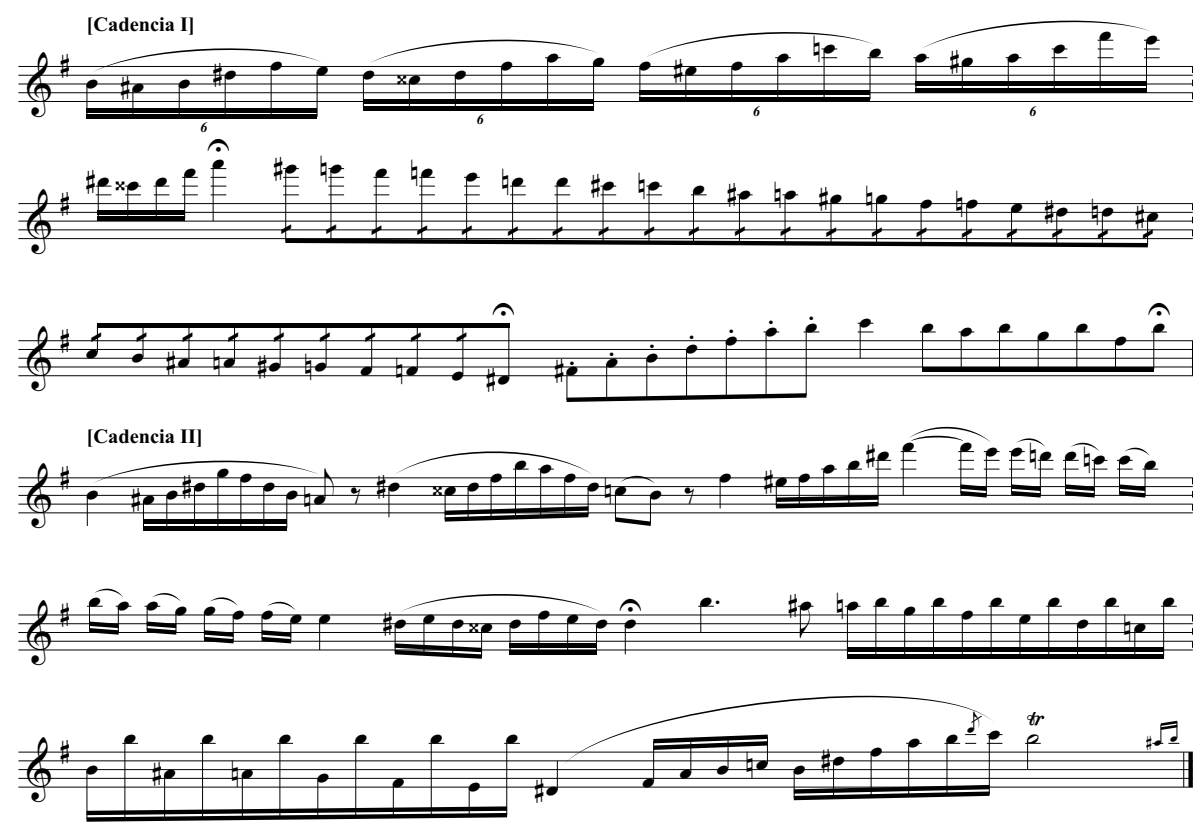

Ejemplo 1. Cadencia I, particella de flauta. Cadencia II, partitura general

el flautista que interpretaba las obras de cámara, Espino era el violinista que tocaba en aquellas obras que requerían de dicho instrumento, ya fueran obras con piano, cuartetos e incluso el Concierto $n .^{\circ} 1$ para violín $y$ orquesta de Charles-Auguste de Beriot ${ }^{33}$.
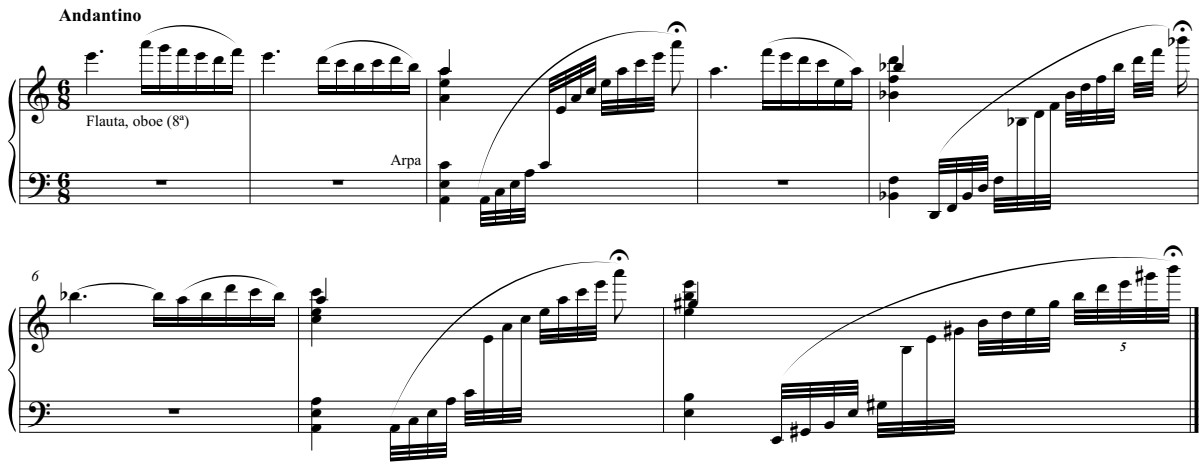

Ejemplo 2. Comienzo de La ausencia, melodía moruna de Casimiro Espino

33 Concierto interpretado el 21-2-1873. 


\section{A modo de conclusiones}

El salón pequeño de la Escuela Nacional de Música y Declamación fue durante un corto periodo de tiempo, comprendido entre 1872 y 1874, el lugar que albergó las actuaciones de la Filarmónica de Madrid. Esta agrupación, cuya misión era la de fomentar el arte musical, no solo difundió la música de cámara, sino que también se centró en el repertorio sinfónico, como estaban haciendo en esa misma época la Sociedad de Conciertos de Madrid o, más tarde, la Unión Artístico Musical. El conservatorio madrileño al ser el centro más importante de enseñanza musical en España se convirtió en un espacio apto para la difusión de la música, pero además se instauró como un emplazamiento de sociabilidad, ideal para personalidades del mundo aristocrático y del poder. Encontramos una dualidad en relación con los espacios que se adscriben a la Filarmónica. Por un lado, la Escuela Nacional de Música y Declamación era un ente público, que acogía a estudiantes indistintamente de su posición social; por otro lado, el público asistente a estos conciertos estaba muy limitado, tanto por el espacio, como por el lugar que ocupaban en la pirámide social de la época. Esta condición social concordaba perfectamente con los fundadores de la agrupación, miembros de la élite social del momento. El salón privado de las grandes casas madrileñas salió con la Filarmónica de Madrid hacia un lugar público, pero sin acceso a todo el mundo, fomentando con ello la difusión de cada acto en la prensa. Lo que quedaba tras las grandes puertas palaciegas y casas burguesas, se trasladó al salón pequeño del Conservatorio.

La agrupación mostró interés por la interpretación de obras creadas expresamente para ella. En este sentido, compositores como Fermín María Álvarez, Joaquín Valverde, Soledad Bengoechea, Casimiro Espino, Enrique Broca, José Inzenga y Manuel de la Mata compusieron obras destinadas a los conciertos de la Filarmónica. La predilección por composiciones cortas es un hecho ya sumamente demostrado, y así se ve en las oberturas, melodías y fantasías que aparecen recogidas en los programas de concierto. La conservación de algunas de estas obras en la Biblioteca del Real Conservatorio Superior de Música de Madrid - enumeradas en el artículo-, engrosa el repertorio de compositores españoles que dedicaron su talento al terreno sinfónico, justo en los años cruciales que permitieron un mayor desarrollo. Estas obras no podrían existir en la manera en que están construidas si no fuera por la estrecha relación que existió entre la Filarmónica y los compositores. Saber que entre los miembros de la orquesta estaban el marqués de Bogaraya, el de Martorell o músicos profesionales como Espino, Beck o Mirecki hizo que se crearan obras pensadas para estos instrumentistas.

La figura de Fermín María Álvarez y de su mujer Eulalia Goicoerretea merecen ser reseñados como grandes mecenas de la música del siglo XIX. 
Gracias a su actividad e interés, junto a su círculo de amistades, nació la ahora conocida Filarmónica de Madrid.Todavía no está todo escrito sobre esta breve sociedad, pues se abren numerosas vías de estudio para el futuro. La posible aparición de nuevos documentos entre los legajos que están siendo catalogados en el Real Conservatorio Superior de Música de Madrid podrían aportar más luz sobre su desarrollo. El papel de la mujer en la sociedad y sobre todo el de la compositora Soledad Bengoechea ya están siendo objeto de estudio para futuros trabajos.

\section{Apéndice 1. Reglamento de la sociedad la Filarmónica de Madrid}

Objeto de la Sociedad

Artículo 1. ${ }^{\circ}$. Esta Sociedad tiene por objeto fomentar el arte musical, celebrando academias para sus ensayos, verificando cuantos conciertos permita el estado de sus fondos.

\section{De los socios}

Artículo 2. ${ }^{\circ}$. La Filarmónica de Madrid se compone de un número de socios indeterminado, dividido en las tres clases siguientes:

Socios de número

De mérito

Honorarios

Artículo $3 .^{\circ}$. Los socios de número se clasifican en activos y pasivos: son activos los que, poseyendo un instrumento o el canto, tomen parte en ensayos y conciertos. Pasivos, los que por su afición o amor al arte gusten cooperar al sostenimiento de esta Sociedad.

Artículo 4. ${ }^{\circ}$. Los de mérito son aquellos que, dedicándose al profesorado, tomen parte en los ensayos y conciertos sin haber llegado a obtener un grado de perfeccionamiento que los haga acreedores al título de honorario.

Artículo 5. ${ }^{\circ}$. Socios honorarios serán los que por su consumado saber, especiales conocimientos en el arte y composiciones lo merezcan.

Artículo 6. ${ }^{\circ}$. Las señoras que tomen parte en los conciertos se consideran socios honorarios.

Artículo $7^{\circ}$. Para inscribirse como socio de número se solicitará del Presidente en una esquela firmada por el aspirante y un socio además.

Artículo $8 .^{\circ}$. Se concederá el título de socio de mérito a los expresados en el artículo $4 .^{\circ}$, por la Junta directiva de acuerdo con el Jurado de la orquesta.

Artículo $9 .^{\circ}$. El título de socio honorario se conferirá de la misma manera que el de mérito, con la sola diferencia de que debe dar dictamen el Jurado de la orquesta.

Artículo $10 .^{\circ}$. Luego que se admita un socio se lo avisará por la Secretaría, remitiéndole un ejemplar de este Reglamento.

Obligaciones de los socios

Artículo $11 .^{\circ}$. Los socios de número satisfarán a su entrada y por una sola vez la cuota de 40 reales. 
Artículo 12. ${ }^{\circ}$. Los socios de número activos contribuirán mensualmente con la cuota de 8 reales, y los socios de número pasivos con la de 20 reales: ambas se cobrarán adelantadas. Los socios de mérito y honorarios están exceptuados del pago.

Artículo $13 .^{\circ}$. El socio que dejare de satisfacer dos mensualidades consecutivas será excluido de la Sociedad.

Artículo $14 .^{\circ}$. La Junta directiva podrá separar a cualquier socio que se niegue sin fundado motivo a tomar parte en los trabajos que le correspondan.

Artículo $15 .^{\circ}$. Los socios activos tienen la obligación de asistir con puntualidad a las academias y conciertos.

Artículo $16^{\circ}$. Las señoras de la sección de canto la tienen de tomar parte en los coros.

De la Junta directiva

Artículo 17. ${ }^{\circ}$. Esta Sociedad será regida por una Junta directiva, que se compondrá de:

Presidente

Tesorero

Contador

Dos secretarios

Archivero

Tres vocales

Artículo $18 .^{\circ}$. Sus atribuciones son:

1. Cumplir y hacer guardar las prescripciones del Reglamento vigente.

2. Designar las cantidades que hayan de satisfacerse a las personas que presten algún servicio.

3. Convocar la Junta general al empezar y finalizar la temporada o año filarmónico, para rendimiento de cuentas y elecciones. Además podrá convocar también a la Junta general cuando lo juzgue oportuno.

4. Admitir socios.

5. Reunirse una vez al mes, a fin de disponer lo que crea útil para el buen régimen de la Sociedad, sin perjuicio de verificarlo siempre que las circunstancias lo exijan.

6. Nombrar comisiones cuando lo estime conveniente.

7. Cuidar de que en todos los actos de la Sociedad se observe el mejor orden y compostura.

8. Fijar, de acuerdo con los socios activos, los días de academia, como también la época de principiar y finalizar la temporada.

9. Señalar el número de billetes de señoras que deban darse a cada socio para los conciertos.

10. Disponer da las cantidades necesarias para atender a los gastos que ocurran, siempre que haya fondos para ellos. Si contrajese deudas sin estar facultada al efecto, ella sola será la responsable, y de ninguna manera la Sociedad.

11. De acuerdo con los directores de orquesta, fijar el orden de los programas y elección de piezas.

Artículo 19. ${ }^{\circ}$ El Presidente presidirá todas las reuniones y actos de la Sociedad. Como jefe de ella, reasume en si todas las facultades y poderes de la misma; en caso de necesidad resolverá cualquiera dificultad que ocurra, debiendo no obstante someter sus disposiciones a la Junta directiva. Firmará las comunicaciones y acuerdos. 
Artículo 20. ${ }^{\circ}$. El tesorero llevará el libro de ingresos y gastos. Pagará los documentos y cuentas que se le presenten, siempre que vayan firmadas por el contador o el que haga sus veces, con tal de que no excedan del límite señalado por la Junta directiva. Cobrará las cuotas mensuales de los socios, por los recibos que le entregue la secretaría, de cuyo importe dará cuenta, así como de los gastos, en Junta directiva.

Artículo 21. ${ }^{\circ}$. El contador intervendrá todos los ingresos y gastos de la Sociedad.

Artículo $22 .^{\circ}$. El secretario $1 .^{\circ}$ llevará un libro de actas y otro para la inscripción de socios. Pasará al depositario una lista de los de número que sean admitidos cada mes, y una nota de los gastos ordinarios y extraordinarios acordados por la directiva.

En la inscripción de socios anotará los nombres y señas de su habitación, colocando a cada uno en la clase o sección que corresponda. Hará todas las citaciones quo el presidente ordene.

Artículo $23 .^{\circ}$. El secretario $2 .^{\circ}$ ayudará al $1 .^{\circ}$ en sus obligaciones, sustituyéndole en sus ausencias, y presidirá la comisión de etiqueta.

Artículo 24. ${ }^{\circ}$. El archivero formará, con intervención del secretario $2 .^{\circ}$, un catálogo de las piezas existentes, con expresión de su procedencia y papeles de que consten, y un inventario de los efectos de que se haga cargo, de cuyos documentos se harán dos copias que firmará con el secretario, de las cuales una quedará en su poder y la otra se custodiará en Secretaría. Siempre que haya aumento de música firmará el correspondiente cargareme.

Tendrá numeradas las piezas y arreglados los papeles que necesiten, entregando al director de orquesta los que pida para ejecutarse en las academias y conciertos.

Artículo 25 . $^{\circ}$. Los tres vocales formarán la comisión de etiqueta, y sustituirán por antigüedad a los demás individuos de la junta.

Artículo $26 .^{\circ}$. De los tres vocales, uno debe pertenecer a los socios honorarios de la orquesta.

Artículo 27. ․ La Junta Directiva elegirá de entre sus individuos el vicepresidente.

\section{De la Junta General}

Artículo 28. ${ }^{\circ}$. La Junta General se compone de todos los socios de número, y no podrá deliberar sin la concurrencia de la cuarta parte de ellos y de cuatro individuos de la Junta Directiva. Si no hubiere número suficiente para deliberar en la primera se convocará a la segunda, y se tomará acuerdo sea cual fuere el número de asistentes.

\section{De los conciertos}

Artículo 29. ․ Para los conciertos, la comisión de etiqueta vigilará que los dependientes observen lo prevenido, evitando la entrada de los que no presenten billete o presenten uno que no les pertenezca. Tendrá además a su cuidado la colocación de las señoras en el salón.

Artículo $30 .^{\circ}$. No se permitirá la entrada en los conciertos a otros caballeros que a los señores socios $y$ transeúntes, cuyo billete deberá solicitarse por un socio y por escrito a la Junta Directiva.

Artículo 31 . $^{\circ}$ Esta petición expresará el nombre, apellido y residencia del transeúnte presentado.

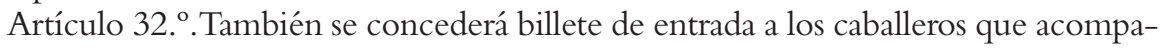
ñen a alguna de las señoras socias honorarias siempre que sean parientes inmediatos. 
Artículo $33 .^{\circ}$. Los billetes todos serán personales e intrasmisibles. El socio es responsable del suyo, y dejará de pertenecer a la Sociedad si le diere.

Artículo 34. ${ }^{\circ}$. Todo socio que se ausente pagará a su regreso dos meses y el corriente.

Aprobado en Junta General.

Madrid, 11 de julio de 1873.

El presidente,

El secretario 1. ${ }^{\circ}$,

Marqués de Bogaray

Ernesto Creus

Apéndice. 2. Lista de los individuos que componen la Filarmónica de Madrid que se publica por acuerdo de la Junta General ${ }^{34}$

Junta Directiva

Presidente: Marqués de Bogaraya

Tesorero: Marqués de Martorell

Contador: Francisco Gener

Archivero: Manuel Fernández Hidalgo

Secretarios: 1. $^{\circ}$, D. Ernesto Creus; 2. ${ }^{\circ}$, D. Mariano Ahumada.

Vocales: Conde de Peña de Ramiro, D. Baldomero Monet y D. (sin elegir).

\section{Sociedad Filarmónica de Madrid}

Socios activos: Álvarez (D. Fermín), Bogaraya (Sr. Marqués de), Creus (D. Ernesto), Carrillo (Andrés), Calderón (D. Laureano), Danis (Eduardo), Fernández (D. Aurelio), Gerner (D. Francisco), Hidalgo (D. Manuel), Martorell (Sr. Marqués de), Montes (D. Mariano), Montes (D. Mariano), Monet (D. Baldomero), Navone y Canepá (D. Francisco), Rubio (D. Roberto), Rodríguez (D. Antonio), Villeti (D. Luis).

Socios honorarios: Arrieta (D. Emilio), Amato (D. Francisco), Aguilar (D. Manuel), Beck (D. Carlos), Barbieri (D. Francisco Asenjo), Brocca (D. Enrique), Beltrán (D. Carlos), Benavent (D. Miguel), Comta (D. Eduardo) Cobeña (D. Antonio), Castro (D. Juan), Caballero (D. Manuel Fernández), Eslava (D. Hilarión), Espino (D. Casimiro), Espín (D. Joaquín), Fernández (D. Tomás), Fernández (D. Manuel), Font (D. Luis), Guelbenzu (D. Juan), González (D. Francisco), González (D. Eusebio), Gauna (Sr. Marqués de), Hernando (D. Rafael), Herrero y Sesé (D. Mariano), Inzenga (D. José), Lestan (D. Tomás), López Juarranz (D. Eduardo), Monasterio (D. Jesús), Mirecki (D.Víctor), Marqués (D. Miguel), Mata (D. Manuel), Morelli (D. José), Majesté (D. Emilio), Nicari (D.V.), Oudrid (D. Cristóbal), Olivares (D.Antonio), Pérez (D. Saturio), Peña (D. Francisco), Páramo (D. Lorenzo), Pardo (D. Manuel), Quiles y Segura (D. Teodoro), Rubio (D. Antonio), Romero (D. Antonio), Rodríguez (D. Manuel), Saiz del Campo (D. Eduardo), Sos (D. Antonio), Scuadrani (D. José), Soriano Fuertes (D. Mariano), Scozdopole (D. Daniel), Torá (D. José), Urrutia (D. Pedro), Zubiaurre (D.Valentín), Zabalza (D. Dámaso).

Socias honorarias: Armenta (Dña. Concepción), Buzón (Dña. Elena), Cimarro (Dña. Isabel), Carrillo de Albornoz (Dña. María), Campos (Dña. Elvira), Correa (Dña.

${ }^{34}$ CMadrid, Imprenta de la viuda de Aguado e Hijo, Pontejos 8, 1873. 
Pilar), Espín y Colbrand (Dña. Ernestina), Franco de Pineda (Dña.Aurea), Fernández de Neda (Dña. Carmen), Hoeffer y Sardin (Dña. Luisa), Izquierdo (Dña. Rosa), Luxan (Dña. Elisa), Martínez (Dña. Amalia), Mantilla (Dña. María), Moreno (Dña. Juana), Munilla (Dña. Clara), Martín (Dña. María), Padilla (Dña. Elvira), Portas (Dña. Adela), Pérez Ibiza (Dña. Matilde), Roca (Dña. Gabriela),Valdés y Pagés (Dña.Teresa),Vallejo (Dña. Rosario), Vallejo (Dña. Concepción).

Socios pasivos: Adeé (D. Augustus A.), Ameller (D. Narciso), Alcañices (Sr. Marqués de), Ahumada (D. Mariano), Ahumada (D. José), Angulo y Rodón (D. José), Arrieta (D. José Joaquín), Avila y Ruano (D. Manuel), Arriola (D. Alejandro María de), Bertodano (D. Emilio), Beccar (Doña Amalia), Bengoechea (D. Aurelio), Belza (D. Miguel), Campuzano (D. Antonio), Carcer (D. Mariano), Caballero y Parga (D. José), Cantillana (Sr. Conde de), Casa-Irujo (Sr. Marqués de), Carrasco (D. Pio Agustín), Castells (D. Juan), Campuzano (D. Carlos), Carbalhal (Sr. Conde de), Conrote (D. Luis), Cambís (Sr. Marqués de), Céspedes (D. Miguel), Cort (D. Pedro), Cotoner (D. José), Díaz (D. Rafael), Donadío (Sr. Conde de), Esperanza (D. José), Elola y Heras (D. Manuel), Enríquez (D. Cayetano), Estéfani (D. Eduardo G. de), Fernán-Nuñez (Sr. Duque de), Frankel (Mr.), Fernández Neda (D. Rafael), Ferraz (D. Rafael), Ferratges (D. Antonio), Figueras (D. Fermín, Fernández de Velasco (D. Bernardino), Goicoerrotea (D. Ramón), García Romero (D. Eduardo), García Santisteban (D. Rafael), Gutiérrez Bustillo (D. José), Gómez Acebo (D. José), Gorostegui (D. Joaquín), Gallar (Dña. Emilia Leones, viuda de), Gabiedes (D. Eduardo G. de), Gutiérrez Ossa (D. José), Gordon y Doz (D. Alejandro J.), Heredia (D. Ricardo), Hurtado de Saldivar (D. José), Huertos (D. Rafael), Imaz y Esteban (D. Rafael de), Jofre (D. Joaquín), Limbillo (D. Gabriel), López (D. Salvador), López Doriga (D. Joaquín), León (D. Luis), León y Apalátegui (Juan José de), Larios (D. Manuel de), Medinasidonia (Sr. Duque de), Manzanera (Sr.Vizconde de), Mondéjar (Sr. Marqués de), Monistrol (Sr. Marqués de), Muchada (D. Pedro), Méndez (D. Juan), Martín Pérez (D. Fausto), Montalvo (D. Sebastián), Manchón y Romero (D. Enrique), Melchor (D. Ricardo), Montero (D. Cayetano), Muro (D. José), Morales y Serrano (D. Juan de), Ortega (D. Leopoldo), Ortiz y Uztariz (D. Antonio), Olavarri (D. Sabino), Primo de Rivera (D. José), Porta (D. José), Paredes de Nava(Sr. Conde de), Pérez (D. Vicente), Primo de Rivera (D. Sixto), Puente (D. Ramiro), Pollo (D. J.), Pequeño (D. Aquilino), Pequeño (D. Cándido), Peña Ramiro (Sr. Conde de), Piñeiro y Aguilar (D. Ventura), Quesada (D.Adolfo), Quiroga y López (D. Benigno), Rey (D. Luis), Robles (D.Teodoro), Romero (D. Lorenzo), Rivera de Adaja (Sr.Vizconde de la), Rascón (Sr. Conde de), Romana (Sr. Marqués de la), Roger de Galard (Le Comte), Rodríguez (D. Eduardo), Rivas (Sr. Duque de), Rojas (D. Federico), Sánchez Villalba (D. Jacobo), Sikles (Sr. General), Soriano (D. Antonio), Saavedra (D. Ramiro), Saavedra (D. Ramiro), Saavedra (D. Teobaldo), Saavedra (D. Fausto), Samaniego (D. Pedro), San Juán (D. Antonio), Santa Cruz de los Manueles (Sr. Marqués de), Sedano (D. Carlos), Sierra (D. Alfredo), Sidorowitch (Mr), Saint Génois d'Anneancourt (Sr. Conde de), Sedano (D. José), Tamames (Sr. Duque de), Torrecilla (Sr. Marqués de las), Triviño (D. Enrique), Uhagon (D. Joaquín), Villa-Marín (Sr. Marqués de),Vargas (D. Pedro),Valdueza (Sr. Marqués de),Villapaterna (Sr. Conde de),Viamanuel (Sr. Conde de),Villa-Gonzalo (Sr. Conde de),Villanueva de Perales (Sr. Conde de), Villares (Sr. Conde de los), Vera (D. Julio de), Vernouillet (Sr. Conde de), Wener (Mr.), Zabalburu (D. José). 


\section{Apéndice 3. Conciertos organizados por la Filarmónica de Madrid (1872-1874)}

\begin{tabular}{|c|c|c|c|}
\hline Título de la obra & Compositor & Arreglista & $\begin{array}{l}\text { Intérpretes }{ }^{35} / \\
\text { Información }\end{array}$ \\
\hline \multicolumn{4}{|c|}{ CONCIERTO $1 .^{\circ}$ DE LA TEMPORADA $(5-6-1872)^{36}$} \\
\hline Romanza de Le vallon & Gounod & & $\begin{array}{l}\text { Gillermo Lennon Hunt } \\
\text { (c) }\end{array}$ \\
\hline Una flor & Fabaro & & $\begin{array}{l}\text { María Carrillo de } \\
\text { Albornoz (c) }\end{array}$ \\
\hline Canto popular toscano & Giordano & & \\
\hline Cuarteto en mi b, op. 16 (I mov.) & Beethoven & & \\
\hline Dúo para piano y violonchelo & Espadero & & $\begin{array}{l}\text { Adolfo de Quesada (p) y } \\
\text { Víctor Mirecki (vc) }\end{array}$ \\
\hline $\begin{array}{l}\text { Fantasía para orquesta sobre motivos de la ópera } \\
\text { Guillermo Tell }\end{array}$ & Enrique Broca & & \\
\hline Obertura de Le Médecin malgré lui & Gounod & $\begin{array}{l}\text { Fermín María } \\
\text { Álvarez }\end{array}$ & \\
\hline Solo 13 con acompañamiento de cuarteto & Tulen & & \\
\hline Reverie & Schuman & & \\
\hline Obertura de Martz & Flotow & & \\
\hline \multicolumn{4}{|c|}{ CONCIERTO $2 .^{\circ}$ DE LA TEMPORADA (27-6-1872) } \\
\hline \multicolumn{4}{|c|}{ PRIMERA PARTE } \\
\hline Obertura de Le médecin malgré lui & Gounod & Álvarez & \\
\hline Romanza para barítono de la ópera Torquato Tasso & Gounod & & Hunt $(\mathrm{c})$ \\
\hline $\begin{array}{l}\text { L'abbandono, dúo de violonchelos con } \\
\text { acompañamiento de piano }\end{array}$ & Pezze & & $\begin{array}{l}\text { Francisco Gerner (vc), } \\
\text { Mirecki (vc) y Leal (p) }\end{array}$ \\
\hline Aria de tiple de la ópera Faust & Gounod & & Carrillo de Albornoz (c) \\
\hline Le sogne, melodía para orquesta & David & Casimiro Espino & \\
\hline \multicolumn{4}{|c|}{ SEGUNDA PARTE } \\
\hline Trío para piano, violín y violonchelo & Rubinstein & & $\begin{array}{l}\text { Quesada (p), Casimiro } \\
\text { Espino (vl) y Mirecki } \\
(\mathrm{vc})\end{array}$ \\
\hline $\begin{array}{l}\text { Oda a Santa Cecilia para tiple acompañada con el } \\
\text { violonchelo }\end{array}$ & & & $\begin{array}{l}\text { Clara Nueros de Hunt } \\
\text { (c) y Mirecki (vc) }\end{array}$ \\
\hline $\begin{array}{l}\text { Les adieux e L'etranger, dos melodías para } \\
\text { instrumentos de cuerda }\end{array}$ & Rosenhain & Álvarez & \\
\hline Trémolo, aire variado para flauta & Demersseman & & Marqués de Bogaraya (f) \\
\hline $\begin{array}{l}\text { Fantasía para orquesta sobre motivos de la ópera } \\
\text { Guillermo Tell }\end{array}$ & Broca & & \\
\hline \multicolumn{4}{|c|}{ CONCIERTO $3 .^{\circ}$ DE LA TEMPORADA $(8-11-1872)$} \\
\hline \multicolumn{4}{|c|}{ PRIMERA PARTE } \\
\hline Le songe, melodía para orquesta & David & Espino & \\
\hline Cavatina de Giovanna d'Arco & Verdi & & $\begin{array}{l}\text { Adela Cristóbal Portas } \\
\text { (c) }\end{array}$ \\
\hline Trío para flauta, violonchelo $y$ piano & Verregust & & $\begin{array}{l}\text { Marqués de Bogaraya } \\
\text { (f), Mirecki (vc) y Carlos } \\
\text { Beck (p) }\end{array}$ \\
\hline Romanza para soprano de Guillermo Tell & Rossini & & Carrillo de Albornoz (c) \\
\hline Obertura capricho & Álvarez & & $\begin{array}{l}\text { Compuesta } \\
\text { expresamente para esta } \\
\text { sociedad }\end{array}$ \\
\hline
\end{tabular}

35 Se indica con una abreviatura el instrumento que tocaban o si cantaban: (c) cantante, (cb) contrabajo, (crn) cornetín, (f) flauta, (fg) fagot, (tp) trompa, (or) órgano, (p) piano, (vla) viola, (vl) violín, (vc) violonchelo.

${ }^{36}$ El programa se enumera en la prensa sin división, aunque seguramente sí la hubo. 


\begin{tabular}{|c|c|c|c|}
\hline \multicolumn{4}{|c|}{ SEGUNDA PARTE } \\
\hline Cavatina de Il Giuramento & Mercadante & & $\begin{array}{l}\text { Ernestina Espín } \\
\text { Colbrand }(\mathrm{c})\end{array}$ \\
\hline Aria de Emma d'Antiochia & Mercadante & & Cristóbal Portas (c) \\
\hline Conciento para piano (I. Mov) & Mayer & & Amalia Martínez (c) \\
\hline Melodía para orquesta & Schumann & Álvarez & \\
\hline Obertura de Isabelle d'Aragon & Pedrotti & Álvarez & \\
\hline \multicolumn{4}{|c|}{ CONCIERTO $4^{\circ}$ DE LA TEMPORADA (29-11-1872) } \\
\hline \multicolumn{4}{|c|}{ PRIMERA PARTE } \\
\hline Obertura capricho & Álvarez & & $\begin{array}{l}\text { Compuesta } \\
\text { expresamente para esta } \\
\text { sociedad }\end{array}$ \\
\hline Romanza Medjé & Gounod & & Hunt (c) \\
\hline Preludio para orquesta & Inzenga & & \\
\hline Cuarteto para flauta, violín, violonchelo y piano & Michelis & & $\begin{array}{l}\text { Marqués de Bogaraya } \\
\text { (f), Espino (vl), marqués } \\
\text { de Martorell (vc) y Beck } \\
\text { (p) }\end{array}$ \\
\hline Terceto de la ópera I Lombardi & Verdi & & $\begin{array}{l}\text { Elisa de Luxán de Torre } \\
\text { López (c), Hunt (c) y } \\
\text { Baragi [sic] (c); solo de } \\
\text { violín Espino }\end{array}$ \\
\hline \multicolumn{4}{|c|}{ SEGUNDA PARTE } \\
\hline Polonesa & Espino & & $\begin{array}{l}\text { Compuesta } \\
\text { expresamente para esta } \\
\text { sociedad }\end{array}$ \\
\hline La melancolía romanza con orquesta & Zubiaurre & & Luxán (c) \\
\hline Conciento para piano (Andante y allegro) & Mendelssohn & & Beck (p) \\
\hline Obertura de Le médecin malgré lui & Gounod & Álvarez & \\
\hline \multicolumn{4}{|c|}{ CONCIERTO $5 .^{\circ}$ DE LA TEMPORADA (no consta en prensa) } \\
\hline \multicolumn{4}{|c|}{ CONCIERTO $6 .^{\circ}$ DE LA TEMPORADA $(17-01-1873)$} \\
\hline $\begin{array}{l}\text { Conciento para violonchelo y orquesta } n^{\circ} 9 \\
\text { (I mov.) }\end{array}$ & Romberg & & Mirecki (vc) \\
\hline Fantasía para flauta & Demersseman & & $\begin{array}{l}\text { Niño Francisco } \\
\text { González (f) }\end{array}$ \\
\hline [La ausencia] melodía moruna & Espino & & $\begin{array}{l}\text { Compuesta } \\
\text { expresamente para esta } \\
\text { sociedad }\end{array}$ \\
\hline \multicolumn{4}{|c|}{ CONCIERTO $7 .^{\circ}$ DE LA TEMPORADA $(21-2-1873)$} \\
\hline \multicolumn{4}{|c|}{ PRIMERA PARTE } \\
\hline Obertura de Il poeta di campgana & Guglielmi & & $\begin{array}{l}\text { Con la instrumentación } \\
\text { tal como la escribió el } \\
\text { autor }\end{array}$ \\
\hline La serenata, melodía arreglada para flautín & Schubert & & González (f) \\
\hline Aria de La Traviata & Verdi & & Cristóbal Portas (c) \\
\hline Conciento para violín y orquesta $n .^{\circ} 1$ & Bériot & & Espino (vl) \\
\hline $\begin{array}{l}\text { Fantasía para orquesta sobre motivos de la ópera } \\
\text { Guillermo Tell }\end{array}$ & Broca & & \\
\hline
\end{tabular}




\begin{tabular}{|c|c|c|c|}
\hline \multicolumn{4}{|c|}{ SEGUNDA PARTE } \\
\hline La ausencia, melodía moruna & Espino & & $\begin{array}{l}\text { Compuesta } \\
\text { expresamente para esta } \\
\text { sociedad }\end{array}$ \\
\hline $\begin{array}{l}\text { Fantasía para piano y orquesta sobre motivos de la } \\
\text { ópera Lucrezia Borgia }\end{array}$ & $\begin{array}{l}\text { Manuel de la Mata } \\
\text { Mata }\end{array}$ & & Dámaso Zabalza (p) \\
\hline La melancolía, romanza con orquesta & Zubiaurre & & Luxán (c) \\
\hline Trío para flauta, violonchelo $y$ piano & Michelis & & $\begin{array}{l}\text { Marqués de Bogaraya } \\
\text { (f), Espino (vl) y Beck } \\
\text { (p) }\end{array}$ \\
\hline Obertura de Elisa e Claudio & Mercadante & & \\
\hline \multicolumn{4}{|c|}{ CONCIERTO $8^{\circ}$ DE LA TEMPORADA (11-III-1873) } \\
\hline \multicolumn{4}{|c|}{ PRIMERA PARTE } \\
\hline Obertura, capricho & Álvarez & & \\
\hline $\begin{array}{l}\text { Dúo para piano y órgano sobre motivos de la ópera } \\
\text { Fausto }\end{array}$ & Mata & & $\begin{array}{l}\text { Isabel Echevarría (p) y } \\
\text { Manuel de la Mata (or) }\end{array}$ \\
\hline Polonesa de I Puritani & Bellini & & $\begin{array}{l}\text { Aurelia Franco de } \\
\text { Pineda (c) }\end{array}$ \\
\hline Concierto para flauta & Demersseman & & González (f) \\
\hline $\begin{array}{l}\text { Fantasía para orquesta sobre motivos de la ópera } \\
\text { Robert le diable }\end{array}$ & Broca & & \\
\hline \multicolumn{4}{|c|}{ SEGUNDA PARTE } \\
\hline Le sogne, melodía arreglada para orquesta & David & Espino & \\
\hline $\begin{array}{l}\text { Fantasía para piano sobre motivos de la ópera } \\
\text { Jerusalem }\end{array}$ & Gottschalk & & Echevarría (p) \\
\hline $\begin{array}{l}\text { Mira la bianca luna, dúo arreglado para violín, } \\
\text { violonchelo, órgano y piano }\end{array}$ & Rossini & Espino & \\
\hline Rondó de Lucia di Lammermoor & Donizetti & & Franco de Pineda (c) \\
\hline Polonesa & Espino & & $\begin{array}{l}\text { Compuesta } \\
\text { expresamente para esta } \\
\text { Sociedad }\end{array}$ \\
\hline \multicolumn{4}{|c|}{ CONCIERTO 9. ${ }^{\circ}$ DE LA TEMPORADA $(28-4-1873)^{37}$} \\
\hline \multicolumn{4}{|c|}{ PRIMERA PARTE } \\
\hline \multicolumn{4}{|l|}{ [Faltan obras] } \\
\hline Aria del acto I de Lucrezia Borgia & Donizetti & & María Mantilla (c) \\
\hline \multicolumn{4}{|c|}{ SEGUNDA PARTE } \\
\hline Gallia & Gounod & & Estreno en España \\
\hline \multicolumn{4}{|c|}{ CONCIERTO $10 .^{\circ}$ DE LA TEMPORADA (no consta en prensa) } \\
\hline \multicolumn{4}{|c|}{ CONCIERTO $11 .^{\circ}$ DE LA TEMPORADA (14-5-1873) } \\
\hline \multicolumn{4}{|c|}{ PRIMERA PARTE } \\
\hline Genevieve, melodía original para orquesta & $\begin{array}{l}\text { Soledad } \\
\text { Bengoechea }\end{array}$ & & \\
\hline Fantasía para flautín & Demersseman & & González (f) \\
\hline Berceuse & Álvarez & & Carmen de Neda (c) \\
\hline $\begin{array}{l}\text { Fantasía para trompa sobre motivos de la ópera } \\
\text { Poliuto }\end{array}$ & Rossari & & Font $(\mathrm{t})$ \\
\hline Chanson indienne, romanza con orquesta & $\begin{array}{l}\text { Princesa Lise } \\
\text { Trabetzkoi }\end{array}$ & & Espín y Colbrand (c) \\
\hline
\end{tabular}

${ }^{37}$ Según la prensa el concierto debía haberse celebrado el jueves 3 de abril de 1873. La Época, Madrid, 1-IV-1873, p. 4. 


\begin{tabular}{|c|c|c|c|}
\hline \multicolumn{4}{|c|}{ SEGUNDA PARTE } \\
\hline Gallia & Gounod & & Luxán (c) \\
\hline \multicolumn{4}{|c|}{ TERCERA PARTE } \\
\hline La ausencia, melodía moruna & Espino & & \begin{tabular}{|l|}
$\begin{array}{l}\text { Compuesta } \\
\text { expresamente para esta } \\
\text { sociedad }\end{array}$ \\
\end{tabular} \\
\hline Dúo de tiples de Norma & Bellini & & Luxán (c) y Mantilla (c) \\
\hline $\begin{array}{l}\text { Fantasía para orquesta sobre motivos de la ópera } \\
\text { Robert le Diable }\end{array}$ & Broca & & \\
\hline \multicolumn{4}{|c|}{ CONCIERTO $12 .^{\circ}$ DE LA TEMPORADA (05-6-1873) } \\
\hline \multicolumn{4}{|c|}{ PRIMERA PARTE } \\
\hline Andante melódico para orquesta & Broca & & \begin{tabular}{|l|} 
Compuesto \\
expresamente para esta \\
Sociedad
\end{tabular} \\
\hline L'Abbandono, dúo para violonchelos & Prezze & & $\begin{array}{l}\text { Gerner }(\mathrm{vc}) \text { y marqués } \\
\text { de Martorell (vc) }\end{array}$ \\
\hline Cavatina de la ópera Semiramide & Rossini & & Elena Buzón (c) \\
\hline Gran polonesa para piano, op. 22 & Chopin & & José Tragó (p) \\
\hline L'Ardita, vals para orquesta & Ardini & & Espín y Colbrand (c) \\
\hline \multicolumn{4}{|c|}{ SEGUNDA PARTE } \\
\hline Chanson indienne, romanza con orquesta & \begin{tabular}{|l|} 
Princesa \\
Trubetzkoi
\end{tabular} & & Espín y Colbrand (c) \\
\hline Dúo original para dos violines & Monasterio & & $\begin{array}{l}\text { Espino (vl) y Pedro } \\
\text { Urritua (vl) }\end{array}$ \\
\hline Non é ver, romanza & Fito Matei & & Sr. Blanco (c) \\
\hline Hommage á Tulou & Demersseman & & Marqués de Bogaraya (f) \\
\hline Serenata & Espín & & $\begin{array}{l}\text { Mantilla (c) y Espín } \\
\text { Colbrand (c) }\end{array}$ \\
\hline Obertura de La Cenerentola & Rossini & & \\
\hline \multicolumn{4}{|c|}{ SEGUNDA TEMPORADA } \\
\hline \multicolumn{4}{|c|}{ CONCIERTO $1 .^{\circ}$ DE LA TEMPORADA $(30-10-1873)$} \\
\hline \multicolumn{4}{|c|}{ PRIMERA PARTE } \\
\hline Obertura de La Gazza Ladra & Rossini & & \\
\hline $\begin{array}{l}\text { ¿Eternamente!, Romanza con acompañamiento de } \\
\text { violonchelo }\end{array}$ & Ponchielli & & $\begin{array}{l}\text { Luxán (c) y marqués de } \\
\text { Martorell (vc) }\end{array}$ \\
\hline Conciento para piano y orquesta (I. Mov) & Riez & & Martínez (p) \\
\hline Fantasía para cornetín & Nicari & & V. Nicari (crn) \\
\hline $\begin{array}{l}\text { Fantasía para orquesta sobre motivos de la ópera } \\
\text { Otello }\end{array}$ & & González & \\
\hline \multicolumn{4}{|c|}{ SEGUNDA PARTE } \\
\hline Angélica, melodía para orquesta & Valverde & & \\
\hline Cavatina de La Sonámbula & Bellini & & Luxán (c) \\
\hline Dúo de flautas con acompañamiento de orquesta & Romanino & & $\begin{array}{l}\text { Marqués de Bogaraya (f) } \\
\text { y González (f) }\end{array}$ \\
\hline Obertura de La Cenerentola & Rossini & & \\
\hline
\end{tabular}

${ }^{38}$ No se ha encontrado en prensa el listado completo de las obras interpretadas en el segundo concierto de la temporada. 


\begin{tabular}{|c|c|c|c|}
\hline \multicolumn{4}{|c|}{ CONCIERTO $2 .^{\circ}$ DE LA TEMPORADA $(24-12-1873)^{38}$} \\
\hline Trío para piano, violín y violonchelo & Rubinstein & & $\begin{array}{l}\text { Quesada (p), Espino (vl) } \\
\text { y Mirecki (vc) }\end{array}$ \\
\hline Terceto de tiples de Una cosa rara & Martín y Soler & & $\begin{array}{l}\text { Luxán (c), Franco de } \\
\text { Pinedo (c) y Buzón (c) }\end{array}$ \\
\hline Recitado y Aria de las joyas de Faust & Gounod & & Luxán (c) \\
\hline Dúo de flauta y fagot & & & $\begin{array}{l}\text { Marqués de Bogaraya (f) } \\
\text { y Manuel Lucientes y } \\
\text { Torres (fg) }\end{array}$ \\
\hline \multicolumn{4}{|c|}{ CONCIERTO $3^{\circ}$ DE LA TEMPORADA (26-I-1874) } \\
\hline \multicolumn{4}{|c|}{ Primera parte } \\
\hline Obertura de La Clemenza di Tito & Mozart & & \\
\hline Trío $n .^{\circ} 2$ para violín, violonchelo y piano (II mov.) & Meister & & $\begin{array}{l}\text { Espino (vl), Gerner (vc) } \\
\text { y Beck (p) }\end{array}$ \\
\hline Polaca de I Puritani & Bellini & & Franco de Pinedo (c) \\
\hline Concierto para piano & Hummel & & Beck (p) \\
\hline \multicolumn{4}{|c|}{ SEGUNDA PARTE } \\
\hline Sinfonía n. ${ }^{\circ} 2$ (Larghetto) & Beethoven & & \\
\hline $\begin{array}{l}\text { Trío para flauta, violín y piano sobre motivos de la } \\
\text { ópera Rigoletto }\end{array}$ & - & & $\begin{array}{l}\text { Niños González (f), } \\
\text { Fernández (vl) y Bustillo } \\
\text { (p) }\end{array}$ \\
\hline Rondó de I Puritani & Bellini & & Franco de Pinedo (c) \\
\hline Obertura de la ópera Zanetta & Auber & & \\
\hline \multicolumn{4}{|c|}{ CONCIERTO $4^{\circ}$ DE LA TEMPORADA $(2-3-1874)$} \\
\hline \multicolumn{4}{|c|}{ Primera parte } \\
\hline Obertura de la ópera Zanetta & Auber & & \\
\hline Fantasía para flauta acompañada de piano & & & González (f) \\
\hline Balada para piano & Chopin & & Echevarría (p) \\
\hline Tú y yo, romanza para canto y violonchelo & Sidorowitch & & $\begin{array}{l}\text { Luxán (c) y marqués e } \\
\text { Martorell (vc) }\end{array}$ \\
\hline $\begin{array}{l}\text { Fantasía para sexteto sobre motivos de la ópera Les } \\
\text { Huguenots }\end{array}$ & & Vázquez & $\begin{array}{l}\text { Mariano Vázquez (p), } \\
\text { Emilio Majesté (vl), } \\
\text { Manuel Pardo (vl), } \\
\text { Carlos Beltrán (vla), } \\
\text { Miguel Benavent (vc) y } \\
\text { Mariano Sesé (cb) }\end{array}$ \\
\hline La Mendicante & Espino & & \\
\hline \multicolumn{4}{|c|}{ SEGUNDA PARTE } \\
\hline Coro de Sacerdotisas de Horazi e Curioza & Mercadante & & $\begin{array}{l}\text { Coro: señoras de la } \\
\text { sociedad }\end{array}$ \\
\hline $\begin{array}{l}\text { Fantasía para violin y piano sobre motivos de la } \\
\text { ópera Guillermo Tell }\end{array}$ & - & & Espino (vl) y Zabalza (p) \\
\hline La carità, arreglada para quinteto de cuerda & Rossini & Benavent & $\begin{array}{l}\text { Majesté (vl), Pardo (vl), } \\
\text { Beltrán (vla), Benavent } \\
(\mathrm{vc}) \text { y Sesé (cb) }\end{array}$ \\
\hline Brindis de Galatea & & & Espín y Colbrand (c) \\
\hline Obertura de La Clemenza di Tito & Mozart & & \\
\hline
\end{tabular}




\begin{tabular}{|c|c|c|c|}
\hline \multicolumn{4}{|c|}{ CONCIERTO $5 .^{\circ}$ DE LA TEMPORADA (26-3-1874) } \\
\hline \multicolumn{4}{|c|}{ PRIMERA PARTE } \\
\hline Obertura de Zanetta & Auber & & \\
\hline $\begin{array}{l}\text { Trío para flauta violín y piano sobre motivos de la } \\
\text { ópera Rigoletto }\end{array}$ & - & & $\begin{array}{l}\text { Niños González (f), } \\
\text { Fernández (vl) y Bustillo } \\
\text { (p) }\end{array}$ \\
\hline La mendicante, romanza & Mercadante & & Isabel Linarro (c) \\
\hline $\begin{array}{l}\text { Fantasía característica para violonchelo sobre motivos } \\
\text { de la ópera Robert le diable }\end{array}$ & Servais & Broca & Mirecki (vc) \\
\hline \multicolumn{4}{|c|}{ SEGUNDA PARTE } \\
\hline $\begin{array}{l}\text { Trío para violín, chelo, piano y órgano sobre motivos } \\
\text { de la ópera Rienzzi }\end{array}$ & - & & $\begin{array}{l}\text { Espino (vl), Mirecki } \\
\text { (vc), Zabalza (p) y Mata } \\
\text { (or) }\end{array}$ \\
\hline Il povero & Gualtieri & & Adela Cruz (c) \\
\hline Melodía para violín & Bengoechea & & Espino (vl) \\
\hline \multicolumn{4}{|c|}{ CONCIERTO $6 .^{\circ}$ DE LA TEMPORADA (12-V-1874) } \\
\hline \multicolumn{4}{|c|}{ Primera PARTE } \\
\hline Obertura de Martha & Flotow & & \\
\hline Une larme, melodía para violonchelo & Dunkler & & $\begin{array}{l}\text { Marqués de Martorell } \\
\text { (vc) }\end{array}$ \\
\hline Romanza de la ópera Il Giuramento & Mercadante & & Lorinda Gamir (c) \\
\hline $\begin{array}{l}\text { Variaciones para fagot sobre un tema de } \mathrm{La} \\
\text { sonnambula }\end{array}$ & Melhez [sic] & & Lucientes (fg) \\
\hline Fantasía sobre motivos de la ópera Otello & & González & \\
\hline \multicolumn{4}{|c|}{ SEGUNDA PARTE } \\
\hline La mendicante, romanza para orquesta & Espino & & \\
\hline Fantasía triunfal para piano & Gottschalk & & Tragó (p) \\
\hline Dúo de la ópera Saffo & Pacini & & $\begin{array}{l}\text { Gamir (c) y Espín y } \\
\text { Colbrand (c) }\end{array}$ \\
\hline Trémolo, aire variado para flauta & Demersseman & & Marqués de Bogaraya (f) \\
\hline Obertura de La Gazza Ladra & Rossini & & \\
\hline \multicolumn{4}{|c|}{ CONCIERTO $7 .^{\circ}$ DE LA TEMPORADA (2-6-1874) } \\
\hline \multicolumn{4}{|c|}{ Primera PARTE } \\
\hline Obertura de Semiramide & Rossini & & \\
\hline Andante para violonchelo & Mendelssohn & & Gerner (vc) \\
\hline Romanza para bajo & Abellan & & Blasco (c) \\
\hline Conciento para piano y orquesta & Bengoechea & & Beck (p) \\
\hline Revérie española para violonchelo & Marqués & & Mirecki (vc) \\
\hline Mira la bianca, trío & Rossini & Espino & $\begin{array}{l}\text { Gamir (c), Francisco } \\
\text { Peña (c) y Blasco (c) }\end{array}$ \\
\hline \multicolumn{4}{|c|}{ SEGUNDA PARTE } \\
\hline Sexteto para cuerda y piano & Marqués & & $\begin{array}{l}\text { Espino (vl), Mata (vl), } \\
\text { Beltrán (vla), Marqués } \\
\text { de Martorell (vc) Sesé } \\
\text { (cb) y Beck (p) }\end{array}$ \\
\hline $\begin{array}{l}\text { Sonata en Mi para flauta y piano (Andante y último } \\
\text { tiempo) }\end{array}$ & Kuhlau & & $\begin{array}{l}\text { Marqués de Bogaraya }(\mathrm{f}) \\
\text { y María Martín }(\mathrm{p})\end{array}$ \\
\hline Bolero de I vespri siciliani & Verdi & & Gamir (c) \\
\hline $\begin{array}{l}\text { Dúo concertante sobre motivos de la ópera La Muta } \\
\text { di Portici }\end{array}$ & Wolff y Bériot & & Espino (vl) y Beck (p) \\
\hline Obertura de ópera Don Giovanni & Mozart & & \\
\hline
\end{tabular}

